\title{
Caffeates and Caffeamides: Synthetic Methodologies and Their Antioxidant Properties
}

\author{
Merly de Armas-Ricard (D), ${ }^{1}$ Enrique Ruiz-Reyes, ${ }^{2}$ and Oney Ramírez-Rodríguez $\mathbb{D}^{1}$ \\ ${ }^{1}$ Laboratory of Chemistry and Biochemistry, Campus Lillo, University of Aysén, Eusebio Lillo 667, Coyhaique 5951537, Aysén, Chile \\ ${ }^{2}$ Department of Chemistry, Basic Sciences Institute, Technical University of Manabi (Universidad Técnica de Manabi), \\ Av Urbina y Che Guevara, Portoviejo, Manabí, Ecuador
}

Correspondence should be addressed to Merly de Armas-Ricard; merly.dearmas@uaysen.cl and Oney Ramírez-Rodríguez; oney.ramirez@uaysen.cl

Received 29 April 2019; Accepted 25 July 2019; Published 11 November 2019

Academic Editor: Rosaria Volpini

Copyright ( 2019 Merly de Armas-Ricard et al. This is an open access article distributed under the Creative Commons Attribution License, which permits unrestricted use, distribution, and reproduction in any medium, provided the original work is properly cited.

Polyphenols are secondary metabolites of plants and include a variety of chemical structures, from simple molecules such as phenolic acids to condensed tannins and highly polymerized compounds. Caffeic acid (3,4-dihydroxycinnamic acid) is one of the hydroxycinnamate metabolites more widely distributed in plant tissues. It is present in many food sources, including coffee drinks, blueberries, apples, and cider, and also in several medications of popular use, mainly those based on propolis. Its derivatives are also known to possess anti-inflammatory, antioxidant, antitumor, and antibacterial activities, and can contribute to the prevention of atherosclerosis and other cardiovascular diseases. This review is an overview of the available information about the chemical synthesis and antioxidant activity of caffeic acid derivatives. Considering the relevance of these compounds in human health, many of them have been the focus of reviews, taking as a center their obtaining from the plants. There are few revisions that compile the chemical synthesis methods, in this way, we consider that this review does an important contribution.

\section{Introduction}

Polyphenols are secondary metabolites of plants and include a variety of chemical structures, from simple molecules such as phenolic acids to condensed tannins and highly polymerized compounds. The benefits of polyphenols on human health are often ascribed to their potential ability to act as antioxidants $[1,2]$. The phenolic derivatives, such as caffeic acid, catechol, catechin, vanillic acid, eugenol, and thymol, act as natural antimicrobial agents. As components of herbs and spices, that often provide unique flavoring properties, many of these compounds have been used by humans for centuries. These agents protect human health and extend the shelf life of foods [3]. Catechol derivateives with antitumor [4-14], antifungal [15] and antibacterial [16-23] activities, among others $[24,25]$, have been reported in the literature.

There are two fundamental classes of phenolic acids, hydroxycinnamics (C6-C3) and hydroxybenzoics (C6-C1). Caffeic acid (3,4-dihydroxycinnamic acid) is one of the hydroxycinnamate metabolites more widely distributed in plant tissues. It is present in many food sources, including coffee drinks, blueberries, apples, and cider [26], and also in several medications of popular use, mainly those based on propolis. Its derivatives are also known to possess anti-inflammatory [27, 28], antioxidant [29-31], antitumor [32-39] and antibacterial activities [40-42], and can contribute to the prevention of atherosclerosis and other cardiovascular diseases [30, 43].

Although there are many literature reports that address the different caffeate biological activities, much research remains to be done on this family of polyphenols, and new derivatives with potentially higher activity than natural or synthetic products reported can be obtained. In this review, we will show several synthetic methods and the antioxidant activity of these compounds.

\section{Chemical Synthesis of Caffeic Acid Derivatives}

Polyphenol and its derivatives may be obtained through organic synthesis methodologies from caffeic acid itself or from other chemical precursors. 


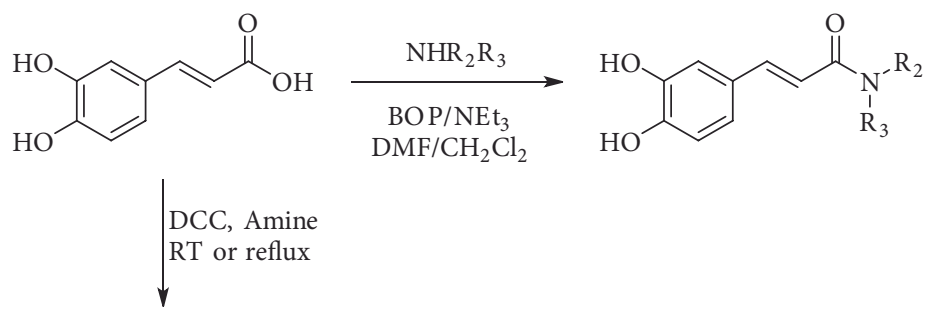<smiles>[R]NC(=O)/C=C/c1ccc(O)c(O)c1</smiles><smiles>CN(C)P(=N)(On1nnc2ccccc21)N(C)C</smiles><smiles>C(=NC1CCCCC1)=NC1CCCCC1</smiles>

DCC reagent<smiles></smiles><smiles>CCN=C=NCCCN(C)C</smiles>

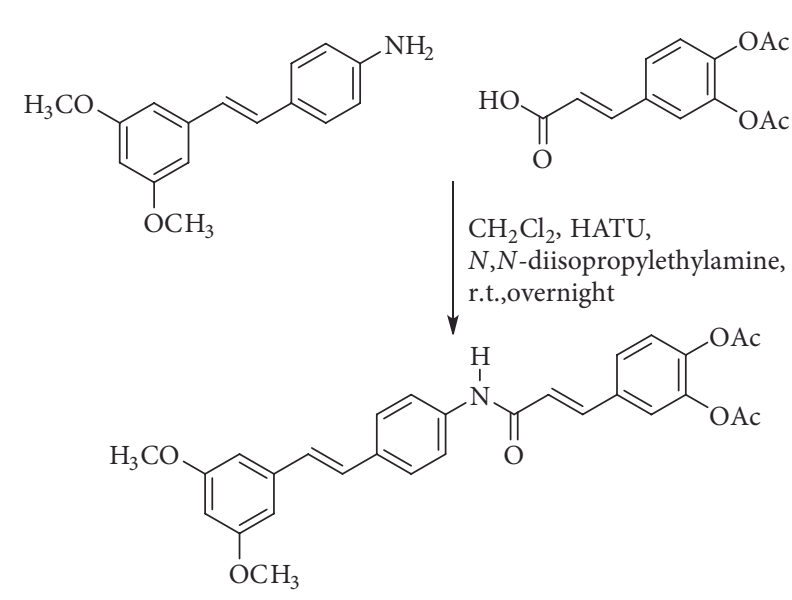<smiles>[13CH3]Oc1ccc(/C=C/C(=O)O)cc1O[13CH3]</smiles>
$\mathrm{n}=1,2,3,5,7,10$ EDC/DMAP/ $\mathrm{CH}_{2} \mathrm{Cl}_{2}$<smiles>CCOc1ccc(/C=C/C(=O)OCCCOc2cc(Cl)ccc2Oc2ccc(Cl)cc2Cl)cc1OC</smiles>

FIGURE 1: Synthesis of caffeic acid amides using some coupling reagents.

Caffeic acid amides and esters have been synthesized by several methods. One of the most common methods is from caffeic acid using coupling reagents, such as (benzotriazol-1-yloxy)tris(dimethylamino)phosphonium hexafluorophosphate (BOP reagent), dicyclohexylcarbodiimide (DCC), 1-(bis(dimethylamino)methylene)- $1 H$-[1,2,3] triazolo[4,5-b] pyridine-1-ium 3-oxide hexafluorophosphate (HATU), and 1-ethyl-3-(3-dimethylaminopropyl)carbodiimide hydrochloride (EDC). Rajan et al. [44], Fu et al. [45], Shi et al. [46], and Jitareanu et al. [47] report the use of BOP to prepare amides from caffeic. Fancelli et al. [48], Arliolo et al. [49], Dai et al. [50], Misra et al. [41], Chen et al. [51], Misra et al. [40], and Liu et al. [52], report the use of DCC. Li et al. [53] report the use HATU, while Kwon et al. [54], Takahashi et al. [55], Chen et al. [56], and Otero et al. [57] report the use of EDC (Figure 1).

Other methods use acetylated caffeic acid. Caffeic acid is acetylated with acetic anhydride in basic media (pyridine or its derivatives [58-60] or sodium hydroxide [61]) to yield di-O-acetyl caffeic acid. This intermediate can be used to prepare amides and esters [62, 63]. Yang et al. [58] synthesize $N$-Propargyl caffeate amide (PACA) transforming this compound into di-O-acetyl-caffeic acid $\mathrm{N}$-hydroxysuccinimide ester via the reaction with $N, N^{\prime}$-disuccinimidyl carbonate in DMF. This ester is transformed in propargyl amide by reaction with the corresponding amine, which simultaneously removes the $\mathrm{O}$-acetyl groups (Figure 2). $\mathrm{N}$-Hydroxysuccinimide esters of $p$-coumaric, ferulic, and caffeic acids are used to transfer hydroxycinnamic moiety to other structures. Stoekigt and Zenk [64] prepared those esters using DCC in dry ethyl acetate and Ishihara et al. [65], using the same protocol, synthesized avenanthramides (Figure 3).

$\mathrm{Di}-\mathrm{O}$-acetyl caffeic acid can be transformed into amides via acid chloride too [59, 66, 67]. Doiron et al. [67] used acetylated caffeic acid to prepare esters and amides; thionyl chloride with catalytic DMF is preferred to obtain esters, while cold oxalyl chloride in dichloromethane is preferred in the synthesis of the caffeamides (Figure 2). The acetyl protecting groups can be removed under basic $[58,62,63,67]$ or acid [ 53 , 

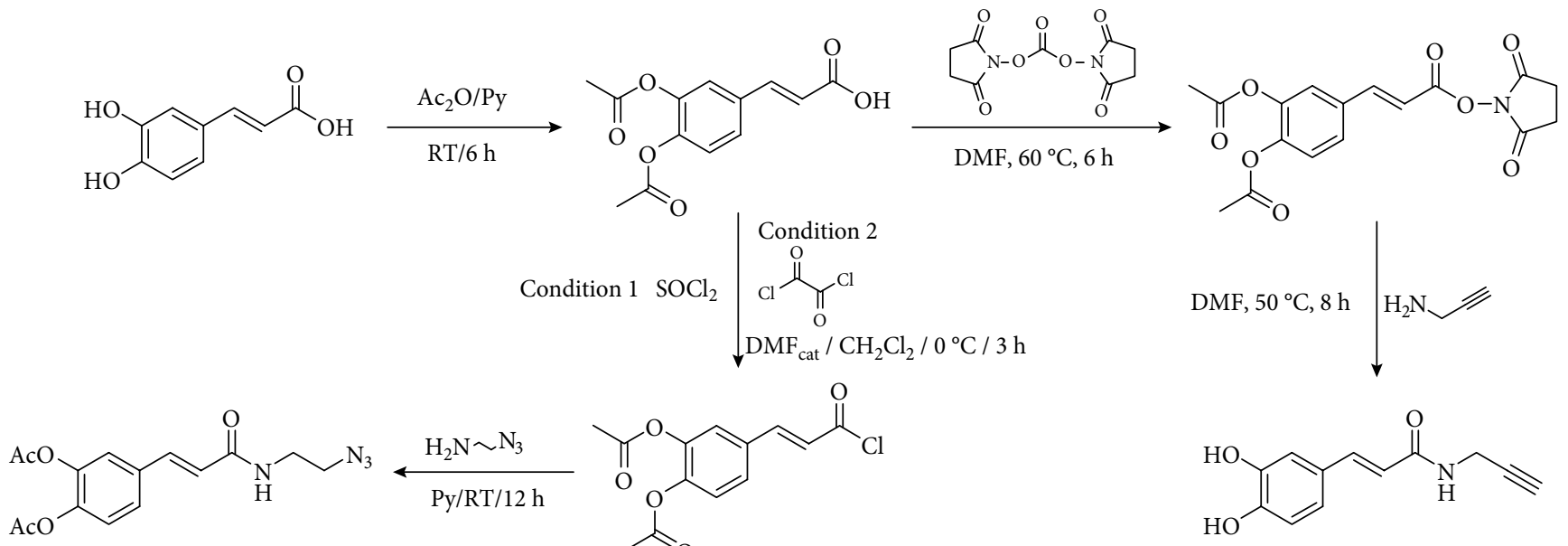<smiles>CC(=O)Oc1ccc(/C=C/C(=O)Cl)cc1OC(C)=O</smiles><smiles>C#CCNC(=O)/C=C/c1ccc(O)c(O)c1</smiles>

(1) $\mathrm{R}-\mathrm{NH}_{2} / \mathrm{Py}$, acetone, $0^{\circ} \mathrm{C}-\mathrm{RT}, 20 \mathrm{~h}$;

(2) $\mathrm{MeOH}, \mathrm{THF}, \mathrm{HCl}, 60^{\circ} \mathrm{C}, 1 \mathrm{~h}$.<smiles>[R]NC(=O)/C=C/c1ccc(O)c(O)c1</smiles>

Figure 2: Synthesis of caffeic acid amides using di-O-acetyl caffeic acid as intermediate.

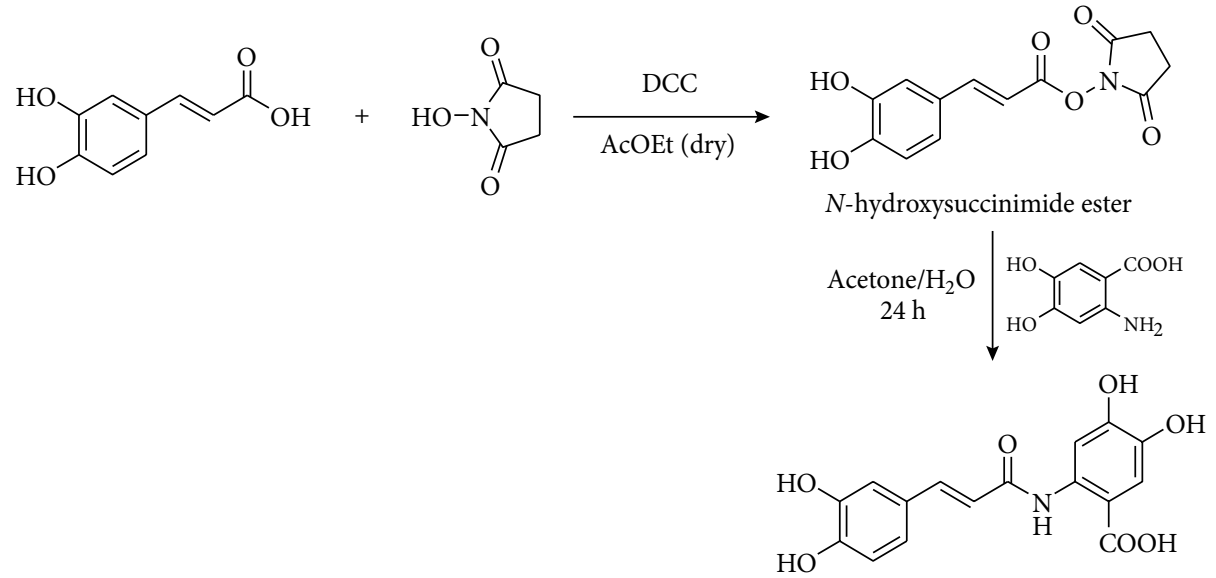

FIGURE 3: Synthesis of avenanthramides reported by Ishihara et al. [65].
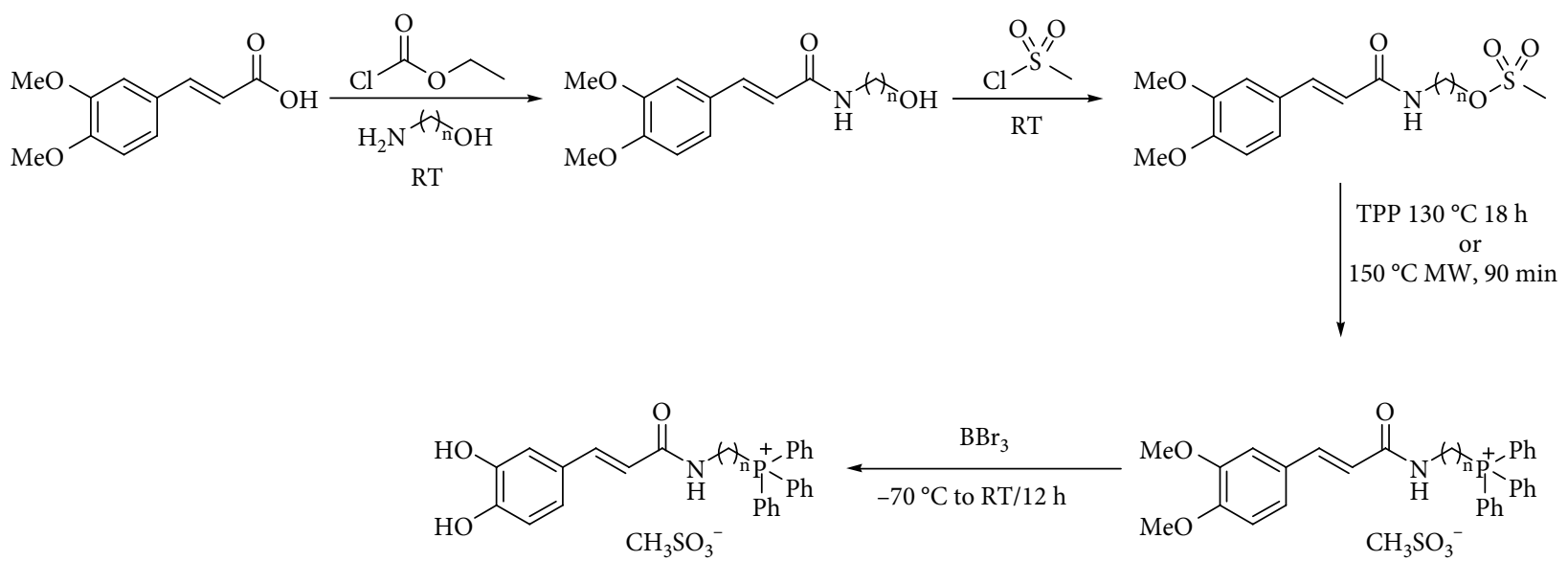

FIGURE 4: Synthesis of caffeic acid derivatives from methylated acid. 


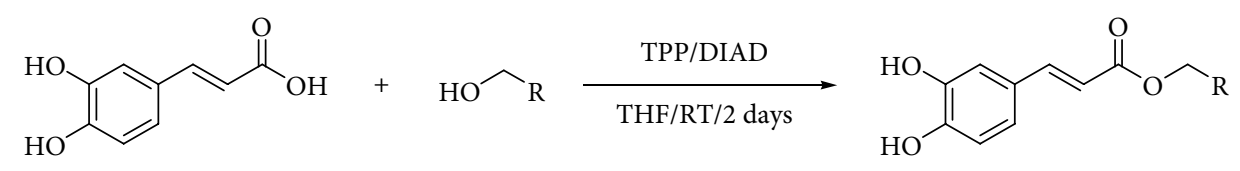

$\mathrm{R}$ = 2-(thiophen-2-yl) ethyl, pyridin-4-ylmethyl, pyridin-3-ylmethyl, 2-(pyridin-2-yl) ethyl, pyridin-2-ylmethyl

FiguRE 5: Synthesis of caffeates by Mitsunobu reaction.

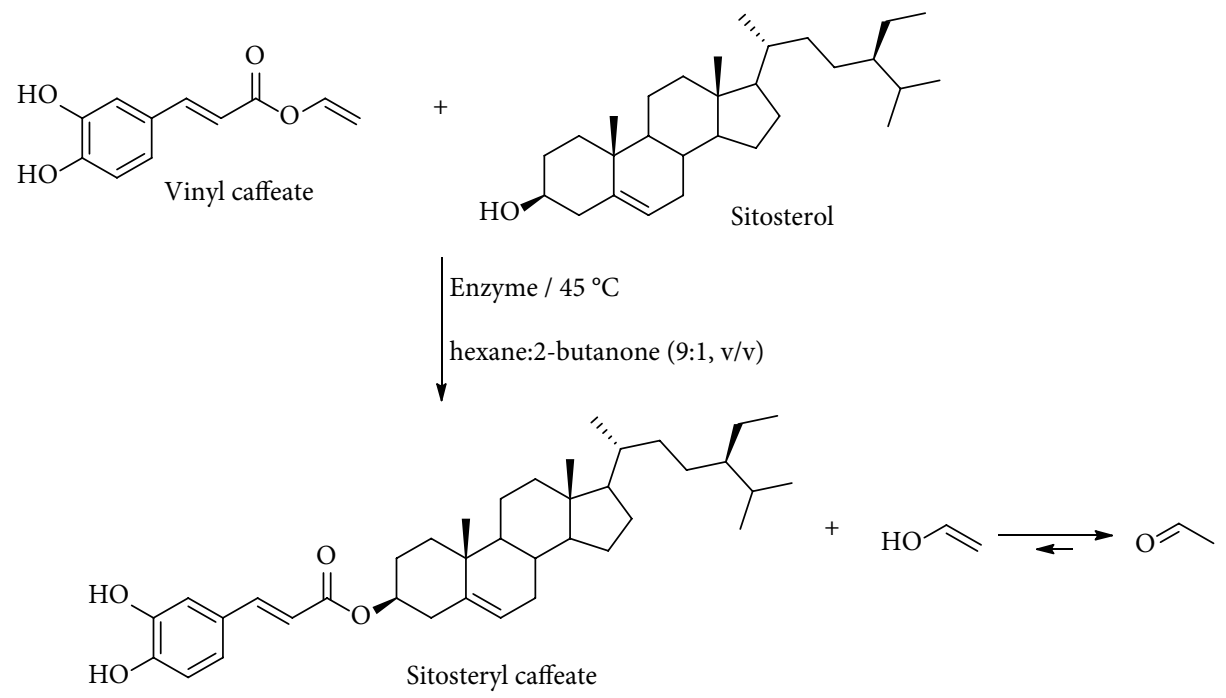

FIGURE 6: Enzymatic transesterification of vinyl caffeate with sitosterol.

59] mild conditions. Other authors use ethyl chloroformate to obtain amides from protected caffeic acid (Figure 4) [68, 69].

Hydroxyl groups of caffeic acid can be protected by methylation too. Amides can be synthesized by all methods already described. Demethylation reaction is carried out using boron tribromide solution (Figure 4) [69, 70].

Caffeic acid alkyl esters can be obtained by many different pathways. Direct esterification (Fisher method) is one of the most used synthetic strategies to obtain esters with a short alkyl chain, using in the most of case sulfuric acid or $p$-toluenesulfonic acid as catalyst [71-74]. Steverding et al. [75] obtain isoamyl caffeate by this method, refluxing isoamyl alcohol, caffeic acid, and sulfuric acid, for 3 hours. Etzenhouser et al. [73] synthesize different alkyl esters using $p$-toluenesulfonic acid and Dean-Stark trap by the Fisher method. Yang et al. [76] obtained bornyl caffeate by the same method some years later. Sørensen et al. [77] report the esterification of caffeic, ferulic, and coumaric acids, catalyzed by acid either added as the strongly acidic sulfonic resin Amberlite IR-120H or as pure sulfuric acid to the reaction medium. Other authors obtain alkyl esters of ferulic and caffeic acid under microwave irradiation, which is not only faster than using conventional heating methods, but also potentially more efficient, clean, and safe [33]. de Campos et al. [78] synthesized caffeic acid esters by the esterification procedure proposed by Fischer with some modifications, they used acetyl chloride as the source of hydrogen chloride catalyst in situ.

There are other methods to synthesize caffeic acid ester. The most common precursors for the synthesis of these compounds are caffeic acid and 3,4-dihydroxybenzaldehyde. From caffeic acid, some authors synthesize alkyl caffeates by nucleophilic displacement of a halogen atom from an alkyl halide in a basic medium $[60,73]$. Other authors prepare those compounds using DCC in different conditions [33, 64, 65]. Paracatu et al. [79] report the use of DCC in dioxane and caffeic acid to prepare methyl, butyl, and heptyl caffeate, stirring for $48 \mathrm{~h}$ at room temperature with a yield between $53 \%$ and $77 \%$. Zhang et al. [80] report the synthesis of many benzyl esters of caffeic acid using DCC in THF, refluxing for 5 hours with much lower yields. Jia et al. [81] use DCC and the esterification reaction was conducted at room temperature for 8 hours. Iqbal et al. [82] obtain guar gum caffeate using DCC in dry DMF at $70^{\circ} \mathrm{C}$ for 48 hours under inert atmosphere. Other reports show the use of DCC with acetylated caffeic acid. Chyba et al. [83] prepared 4-nitrophenyl caffeate by a combination of standard procedures of organic synthesis and enzymatic deacetylation and used it in assays of caffeoyl esterases.

Mitsunobu reaction is used in the synthesis of caffeic acid esters too [84-88]. Hajmohamad et al. [87] used this method (triphenylphosphine (TPP) and diisopropyl azodicarboxylate (DIAD) in dry tetrahydrofuran as solvent at room temperature) to obtain several heterocyclic esters of caffeic acid (Figure 5).

There are many reports of the use of enzymatic methods to obtain esters of caffeic acid. They are mainly transesterification methods. Tan and Shahidi [89] report a novel method for chemoenzymatic synthesis of phytosteryl caffeates through an intermediate vinyl caffeate, which was first chemically 

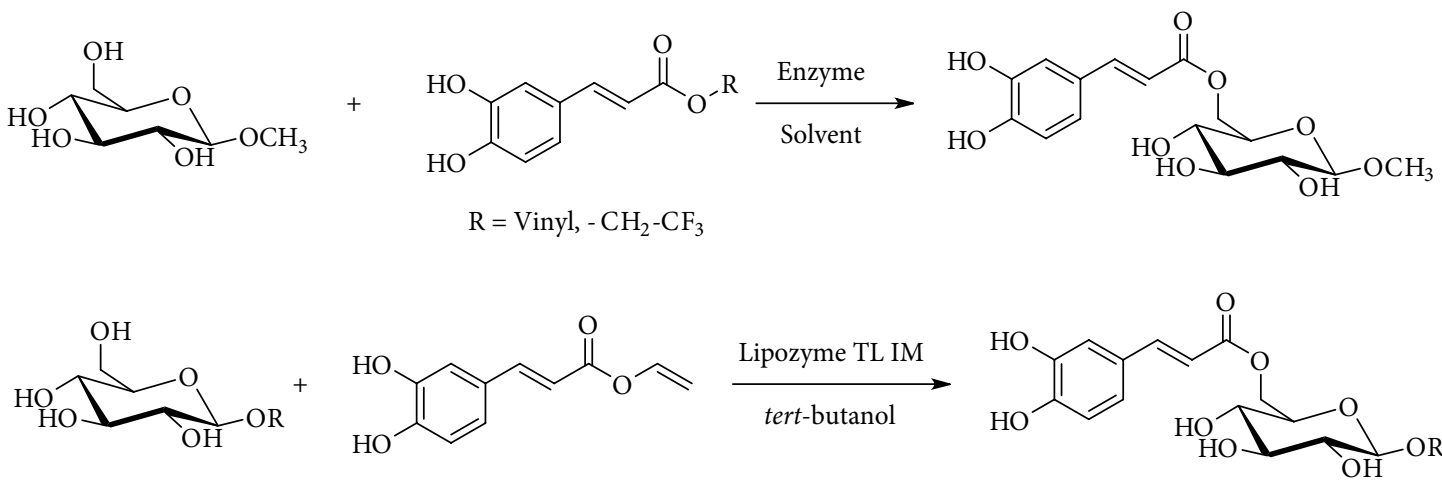

$\mathrm{R}=p$-hydroxyphenyl and 2-( $p$-hydroxyphenyl)ethyl

FIGURE 7: Enzymatic caffeoylation of $\beta$ - $D$-glucopyranosides.<smiles>[R7]OC(=O)/C=C/c1ccc(O)c(O)c1</smiles>

FIGURE 8: Synthesis of caffeates using thionyl chloride reported by Chou et al. [92].

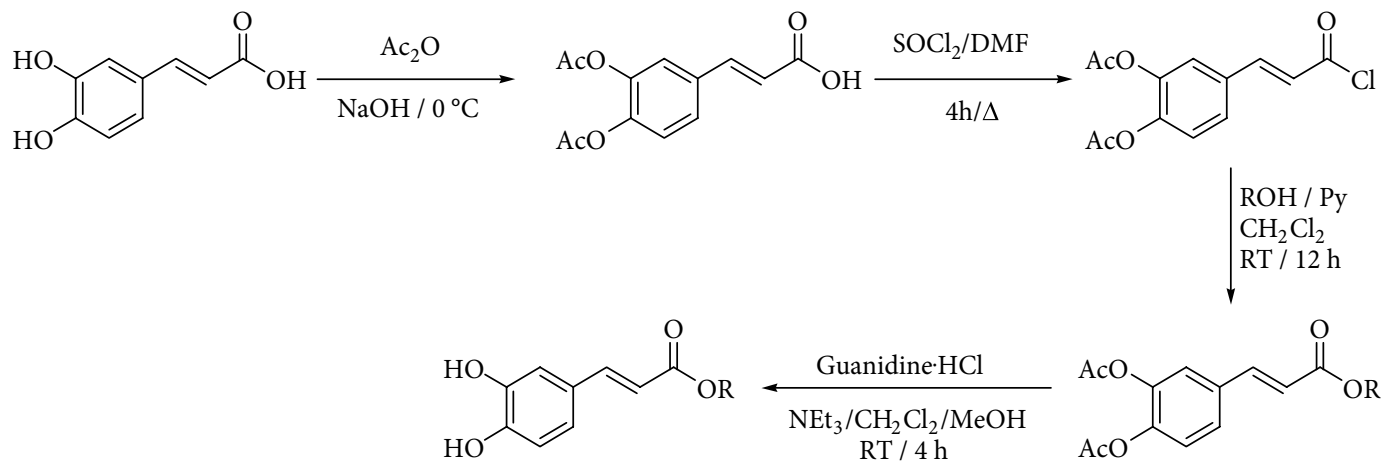

FIGURE 9: Synthesis of esters using acetylated caffeic acid reported by Sanderson et al. [63].
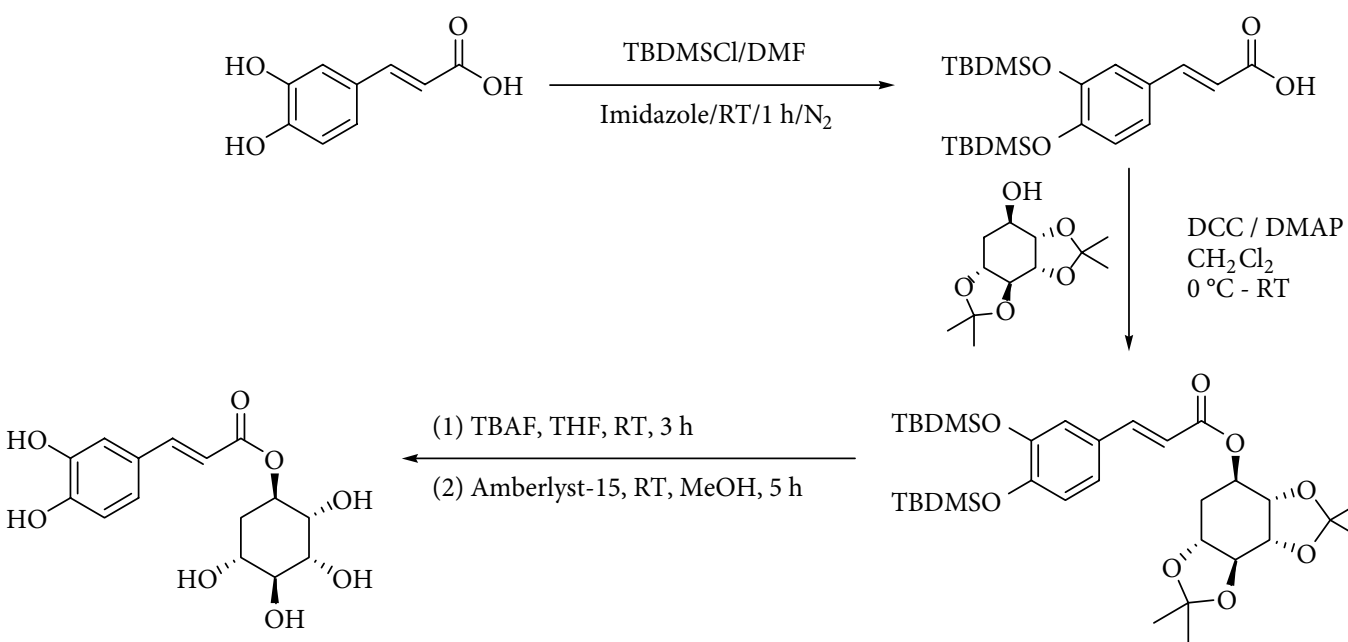

(1) TBAF, THF, RT, $3 \mathrm{~h}$

(2) Amberlyst-15, RT, MeOH, 5 h<smiles>CCCCOc1ccc(/C=C/C(=O)O[C@H]2C[C@@H]3OC(C)(C)O[C@@H]3[C@H]3OC(C)(C)O[C@@H]23)cc1OCC</smiles>

FIGURE 10: Silylation of hydroxyl groups in caffeic acid reported by Rattanangkool et al. [100]. 
<smiles>[R2]OC(=O)/C=C/c1ccc(O)c(O)c1</smiles>

FIGURE 11: Synthesis of caffeic acid esters using ytterbium triflate as catalyst.<smiles>CC(C)(C)OC(=O)/C=C/c1ccc(O)c(O)c1</smiles>

FIGURE 12: Synthesis of $t$-butyl caffeate by Wittig procedure (Etzenhouser et al. [73]).

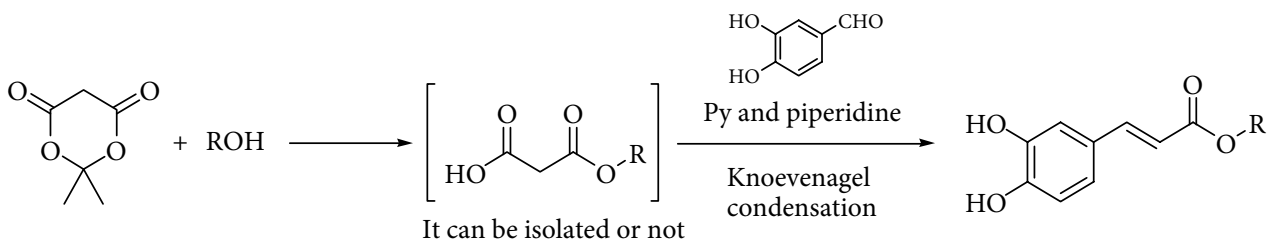

FIGURE 13: Synthesis of caffeic acid derivatives using meldrum's acid.

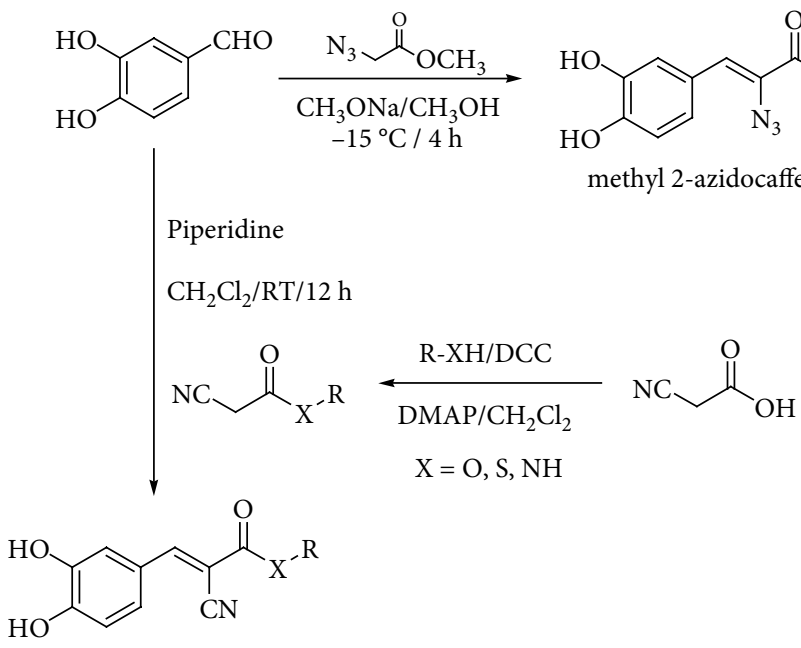

FIGURE 14: Synthesis of caffeic acid derivatives substituted in vinylic position.

produced and subsequently esterified with phytosterols through lipase-assisted alcoholysis (Figure 6). Ten enzymes were initially screened by the authors for their ability in catalyzing the alcoholysis reaction between phytosterols and vinyl caffeate. Lipase from Candida rugosa was the only enzyme that successfully catalyzed that alcoholysis reaction.

Pang et al. [90] report the synthesis of propyl caffeate by an enzymatic method. They prepare this compound by transesterification of methyl or ethyl caffeate and 1-propanol using different lipases in an ionic liquid. The best yield was obtained using $[\mathrm{Bmim}]\left[\mathrm{CF}_{3} \mathrm{SO}_{3}\right]$ as ionic liquid, Novozym 435 as catalyst, 1:20 was the mass ratio methyl caffeate to lipase, and $1: 5$ was the molar ratio methyl caffeate to 1 -propanol. The reaction temperature was $60^{\circ} \mathrm{C}$.

Chyba et al. [91] report the enzymatic caffeoylation of methyl $\beta$-D-glucopyranoside using vinyl and 2,2,2-trifluoroethyl caffeates as caffeoyl donors and a lipase from Thermomyces lanuginosus (Lipozyme TL IM). The regioselective formation of methyl 6-O-caffeoyl- $\beta$ - $D$-glucopyranoside was obtained using vinyl caffeate in tert-butanol and verified with arbutin and salidroside as acceptors (Figure 7).

One of the most common methods reported in the literature for the synthesis of caffeic acid esters uses thionyl chloride as reagent and protected or unprotected caffeic acid in phenolic hydroxyl groups. The most commonly used protection method is acetylation with acetic anhydride. These two methods transform caffeic acid in caffeoyl chloride.

Reaction with unprotected acid is carried out in a dry solvent, heating to reflux under inert atmosphere (nitrogen or argon). The solvent and $\mathrm{SOCl}_{2}$ can be removed under vacuum or not, and then desired alcohol is added under dry conditions. Some authors use a basic medium with alcohol, others do not. 
The most used solvents are dichloromethane, 1,2-dimethoxyethane (DME) and dioxane (Figure 8) [92-96].

Many authors prepare acetylated caffeoyl chloride from acetylated caffeic acid by the Vilsmeier-Haack adduct $[62,63$, $67,97]$, obtained by reaction of thionyl chloride with a catalytic amount of $N, N$-dimethylformamide (Figure 9). That carboxylic chloride can be synthesized from the protected acid and thionyl chloride too [98] or using oxalyl chloride and DMF in dichloromethane [61].

Methylated caffeic acid is also used in the synthesis of esters. These esters can be synthesized by all methods already described [99].

Silylation is another method to protect phenolic hydroxyl groups in caffeic acid [57, 100, 101]. Rattanangkool et al. [100] use tert-butyldimethylsilyl chloride (TBDMSCl) to do that and deprotection was carried out in tetrahydrofuran with TBAF at room temperature for $3 \mathrm{~h}$ (Figure 10).

Xie et al. [102] report a convenient and practical catalytic method for the preparation of caffeic acid esters with high efficiency using ytterbium triflate in nitromethane without any other auxiliary reagents. They obtained between $40 \%$ and $60 \%$ isolated yields without water removal (Figure 11).

Synthesis methods that do not use caffeic acid or its protected derivatives as starting substrates use commonly 3,4-dihydroxybenzaldehyde and by condensation or Wittig reactions obtain the desired compounds.

Wittig reaction can be used to obtain esters or amides [73, $101,103]$. The most commonly used reagents are esters and amides of $\alpha$-haloacetic acid, which, by reaction with triphenylphosphine, produce the corresponding phosphonium salt (Figure 12).

One of the most common condensation methods employs a monoester of malonic acid, which can be isolated or not. This method involves two reactions; the first is the synthesis of malonic acid monoester from meldrum's acid and desired alcohol. The second is the Knoevenagel condensation of malonic acid monoester with 3,4-dihydroxybenzaldehyde in the presence of a base (pyridine and piperidine in most cases) at room temperature for 12-24h (Figure 13) [68, 74, 94, 103-110].

Knoevenagel condensation of 3,4-dihydroxybenzaldehyde with other compounds can be performed to obtain other derivatives of caffeic acid, some of them substituted in vinylic carbons. Sechi et al. [111, 112] synthesized 2-azido3-(3,4-dihydroxy-phenyl)-acrylic acid methyl ester (methyl 2azidocaffeate) as an intermediary to obtain 5,6-dihydroxy- $1 H$-indole-2-carboxylic acid (Figure 14). Rodrigues et al. [113] synthesized cyanoacetic acid derivatives (esters, amides, and thioesters) and obtained the caffeic acid derivatives by Knoevenagel condensation of these compounds with 3,4-dihydroxybenzaldehyde under basic conditions (Figure 14).

\section{Antioxidant Activity}

The reactive oxygen species (ROS) such as superoxide anion radical, hydrogen peroxide, and hydroxyl radical are generated in all cells due to both endogenous metabolic processes as exogenous stimuli. However, cells are usually able to reduce the oxidative potential of ROS by activating several antioxidant systems. In plants, one of these defense systems are polyphenols, making this family of compounds a target for the search for applications in the food and pharmaceutical industries. In this context, it has been reported that some compounds such as caffeic acid (entry 1, Table 1) and its derivatives have antioxidant properties [114]. According to Chung et al. [115] caffeic acid has an antioxidant effect against the oxidative lesions that are produced in the gill cells of trout. A concentration-dependent inhibition of iron-catalyzed lipid peroxidation is, moreover, exerted by esters, as octyl caffeate (0.1-1.0 mM), in rat brain homogenates. It has been shown to have a potent antioxidant when the nitric oxide synthase (iNOS) expression is induced by means of lipopolysaccharides (LPS), and interferon- $\gamma$ (IFN- $\gamma$ ) in cultured primary rat aortic smooth muscle cells (RASMC) in vitro, in addition to induced hypotension by means of LPS in vivo [116]. Recently, Kyselka et al. [117] have reported that caffeic acid and methyl caffeate (entry 2, Table 1) showed the highest reduction rate against the oxidation reaction with the 1,1-diphenyl-2-picrylhydrazyl radical $\left(\mathrm{DPPH}^{\circ}\right)$ showing better results as an antioxidant than other phenolic compounds.

Chapado et al. [86] reported the synthesis of dihydroxyphenetyl caffeate (entry 10, Table 1), among others esters structurally related to rosmarinic acid (entry 11, Table 1), and evaluated their antioxidant activity against $\mathrm{DPPH}^{\circ}$. Those compounds showed better antiradical activity than their precursors (dihydroxyphenetyl alcohol, caffeic, protocatechuic, and gallic acids) and rosmarinic acid. Taguchi et al. [118] also reported the ability of rosmarinic acid derivates as antioxidants (DPPH radical scavenging assay), along with that of certain esters (entries 1-9, Table 1) and amides (entries 15 and 16, Table 1) of caffeic acid. These authors found $61 \%-63 \%$ of DPPH radical scavenging activity for alkyl esters and 2-(3,4-dihydroxyphenyl)ethyl caffeamide, while $\omega$-OH esters and pentyl amide showed $53 \%-55 \%$ of activity. The results suggested that those compounds without catechol moiety (entry 17, Table 1) showed low inhibition percentages even at very high concentrations $(<10 \%$ at $500 \mu \mathrm{M}$ concentration). Therefore, the presence of catechol ring is important in the scavenging action of ROS species. However, they could not find a specific structural feature of caffeic acid-type compounds, having an account that caffeic acid itself has significant antioxidant activity. Amoussa et al. [119] report the antioxidant activity of 3-caffeoylbetulinic acid (entry 12, Table 1), it showed significant antioxidant activity with an $\mathrm{IC}_{50}$ of $3.57 \mu \mathrm{g} / \mathrm{mL}$ compared to quercetin (control) $1.04 \mu \mathrm{g} / \mathrm{mL}$.

Esters obtained from phenolic hydroxyl groups of caffeic acid also show antioxidant activity. Gandolfi et al. [120] report the radical scavenging activity (RSA) towards DPPH of 3 -[(2E,4E,6E)-octa-2,4,6-trienoyl]caffeic acid and 4 -[(2E,4E,6E)-octa-2,4,6-trienoyl]caffeic acid (entry 13, Table 1$)$ and 3,4-di-[(2E,4E,6E)-octa-2,4,6-trienoyl]caffeic acid (entry 14, Table 1). They show, in general, esterification with caffeic acid led to a higher increase in RSA, although the diester did not show higher activity than caffeic acid. 
TABLE 1: Antioxidant activity of caffeic acid derivatives against $\mathrm{DPPH}^{\circ}$.

\begin{tabular}{|c|c|c|c|c|}
\hline Entry & Compound & Structure & $\begin{array}{l}\text { DPPH radical scavenging } \\
\text { activity }^{\mathrm{a}}\end{array}$ & Reference \\
\hline \multirow[t]{5}{*}{1} & \multirow[t]{5}{*}{ Caffeic acid } & & $63 \%(500 \mu \mathrm{M})$ & {$[118]$} \\
\hline & & & $0.17 \mu \mathrm{mol} / \mu \mathrm{mol} \mathrm{DPPH}$ & {$[117]$} \\
\hline & & & $0.17 \mathrm{~mol} / \mathrm{mol} \mathrm{DPPH}$ & {$[86]$} \\
\hline & & & $\mathrm{IC}_{50} 15.3 \mu \mathrm{M}$ & {$[123]$} \\
\hline & & & $\mathrm{EC}_{50} 30.88 \mu \mathrm{M}$ & {$[41]$} \\
\hline \multirow[t]{2}{*}{2} & \multirow[t]{2}{*}{ Caffeic acid methyl ester } & & $62 \%(500 \mu \mathrm{M})$ & {$[118]$} \\
\hline & & & $0.17 \mu \mathrm{mol} / \mu \mathrm{mol} \mathrm{DPPH}$ & {$[117]$} \\
\hline \multirow[t]{2}{*}{3} & \multirow[t]{2}{*}{ Caffeic acid allyl ester } & & $64 \%(500 \mu \mathrm{M})$ & {$[118]$} \\
\hline & & & $\mathrm{IC}_{50} 12.3 \mu \mathrm{M}$ & {$[123]$} \\
\hline 4 & Caffeic acid propyl ester & & $63 \%(500 \mu \mathrm{M})$ & {$[118]$} \\
\hline 5 & Caffeic acid butyl ester & & $62 \%(500 \mu \mathrm{M})$ & {$[118]$} \\
\hline 6 & Caffeic acid pentyl ester & & $62 \%(500 \mu \mathrm{M})$ & {$[118]$} \\
\hline 7 & Caffeic acid hexyl ester & & $61 \%(500 \mu \mathrm{M})$ & {$[118]$} \\
\hline 8 & Caffeic acid heptyl ester & & $63 \%(500 \mu \mathrm{M})$ & {$[118]$} \\
\hline 9 & Caffeic acid nonyl ester & & $61 \%(500 \mu \mathrm{M})$ & {$[118]$} \\
\hline 10 & Caffeic acid 3,4-dihydroxyphenetyl ester & & $0.09 \mathrm{~mol} / \mathrm{mol} \mathrm{DPPH}$ & {$[86]$} \\
\hline 11 & Rosmarinic acid & & $0.12 \mathrm{~mol} / \mathrm{mol} \mathrm{DPPH}$ & {$[86]$} \\
\hline & & & $61 \%(500 \mu \mathrm{M})$ & {$[118]$} \\
\hline 12 & 3-Caffeoylbetulinic acid & & $\mathrm{IC}_{50}$ of $3.57 \mu \mathrm{g} / \mathrm{mL}$ & [119] \\
\hline 13 & $\begin{array}{c}\text { 3- and 4-[(2E,4E,6E)-octa-2,4,6-trienoyl }] \\
\text { caffeic acid }\end{array}$ & & $96.25 \%(5 \mathrm{mM})$ & {$[120]$} \\
\hline 14 & 3,4-Dioctatrienoyl caffeic acid & & $100 \%(5 \mathrm{mM})$ & {$[120]$} \\
\hline
\end{tabular}


TABLE 1: Continued.

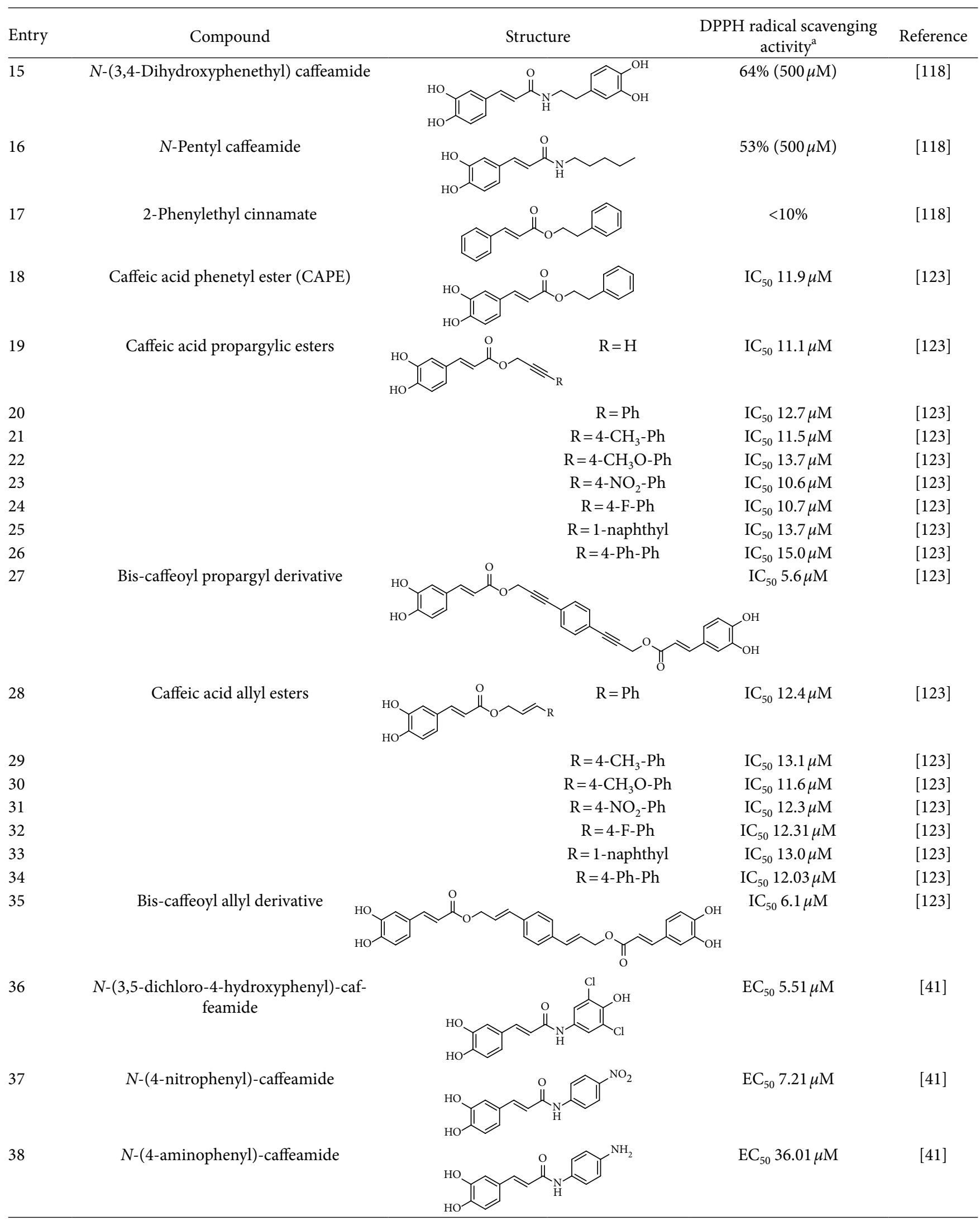

${ }^{\mathrm{a}} \mathrm{IC}_{50}$ : Inhibitory concentration, $\mathrm{EC}_{50}$ : Effective concentration. 
TABLE 2: Lipid peroxidation inhibitory activity of caffeic acid amides and related compounds.

\begin{tabular}{|c|c|c|c|c|}
\hline Entry & Compound & Structure & $\mathrm{IC}_{50}(\mu \mathrm{M})^{\mathrm{a}}$ & Reference \\
\hline 1 & $N$-(2-Hydroxyphenyl) caffeamide & & 0.29 & {$[44]$} \\
\hline 2 & $N$-Phenyl caffeamide & & 0.38 & {$[44]$} \\
\hline 3 & $N$-(3,4-Dihydroxyphenethyl) caffeamide & & 0.59 & {$[44]$} \\
\hline 4 & $N$-Isopentyl caffeamide & & 1.4 & {$[44]$} \\
\hline 5 & Trolox & & 2.8 & {$[44]$} \\
\hline 6 & Caffeic acid & & 3.3 & {$[44]$} \\
\hline 7 & Quercetin & & 0.95 & {$[44]$} \\
\hline
\end{tabular}

${ }^{\mathrm{a}}$ The antioxidant activity of each compound was expressed as $\mathrm{IC}_{50}$ value, i.e., the concentration in $\mu \mathrm{M}$ necessary to inhibit TBARS formation by $50 \%$, and was calculated from the corresponding log-dose inhibition curve.

Rajan et al. [44] synthesized caffeic acid amides and studied their antioxidant properties as lipid peroxidation inhibitory activity. Caffeic acid anilides were very efficient antioxidants with $\mathrm{IC}_{50}$ of $0.3 \mu \mathrm{M}$ (entries 1 and 2, Table 2). The aliphatic amides also showed activity, and were slightly lower than the anilides (entries 3 and 4, Table 2). These amides showed antioxidant activity comparable with standard antioxidants such as Trolox, caffeic acid, and quercetin (entries 5-7, Table 2). $p$-coumaric acid amides are 10 times less active, which suggest that the catechol ring has influence on the antioxidant activity [44].

Lira et al. [121] studied in vitro oxidant and antioxidant activity of isopropyl caffeate in the presence of phenylhydrazine and Reactive Oxygen Species. They showed that no hemoglobin oxidation was observed at concentrations lower than $100 \mu \mathrm{g} / \mathrm{mL}$ (compared to the negative control), but it could not prevent the oxidation of hemoglobin in the presence of phenyl hydrazine. Therefore, there is not significant oxidant power in this substance. Furthermore, the authors noted that isopropyl caffeate was able to react with ROS at concentrations of $10,50,100$, and $250 \mu \mathrm{g} / \mathrm{mL}$. They also discovered that the hemolysis induced by hydrogen peroxide was reduced when compared to the positive control group $\left(\mathrm{Hb}+\mathrm{H}_{2} \mathrm{O}_{2}\right)$, and finally, isopropyl caffeate shows a greater antioxidant power than vitamin $\mathrm{C}$.

On the other hand, Pérez-Cruz et al. [122] have reported the antioxidant activity of coumarin derivatives with phenolic acid moieties against the biologically relevant ROS using assays as oxygen radical absorbance capacity fluorescein
(ORAC-FL), the ferric reducing ability of plasma (FRAP), electronic spin resonance (ESR), and cellular antioxidant activity (CAA). These compounds showed better ORAC-FL values than Trolox, and two or three times more than coumarin moiety alone. Therefore, the polyphenol inclusion in the coumarin scaffold contributes to the antioxidant capacity. The evaluation of ${ }^{\circ} \mathrm{OH}$ scavenging was done by ESR, and the radical-scavenging values indicated that the coumarin caffeic and gallic derivatives were similar and better than the coumarin moiety, and attained values of approximately $99 \%$. The FRAP assay showed that derivatives have values between two and three times higher than their coumarinic precursor, suggesting that the inclusion of phenolic moieties in the original coumarinic scaffold increases the reducing capacity.

Doiron et al. [123] synthesized some propargyl and allyl esters of caffeic acid and assayed their antioxidant activity by employing 2,2-diphenyl-1-picrylhydrazyl (DPPH). All of them showed a good ability radical scavenging with most having $\mathrm{IC}_{50}$ values in the range of $10-15 \mu \mathrm{M}$, being similar to the radical scavenging activity of caffeic acid $(15.3 \mu \mathrm{M}$, entry 1 Table 1$)$ and CAPE $(11.9 \mu \mathrm{M}$, entry 18 Table 1$)$. The authors found little differences in radical scavenging activity of monovalent esters of both series (propargyl and allyl esters; entries $3,19-26$, and 28-34, Table 1; respectively). These findings indicate that the antioxidant activity of caffeic acid catecholic ring is practically insensitive to changes that do not directly alter it. Derivatives with two catechol rings (dimers of caffeic acid derivatives, entries 27 and 35, Table 1) have twice as much antioxidant activity as monoesters. 
Finally, Misra et al. [41] report on the antioxidant and antibacterial activities of a new caffeamide series (entries 36-38, Table 1). They observed that amides having electron withdrawing group attached had lower $\mathrm{EC}_{50}$ value than caffeic acid. They behave more potent antioxidant with respect to caffeic acid, whereas electron donating moiety attached with caffeamide had a higher $\mathrm{EC}_{50}$ value compared to caffeic acid, as expected.

\section{Conclusions}

In addition to extraction from natural sources, there are cheap and easy to make synthetic methods for obtaining caffeic acid derivatives. These methods, unlike the extractive ones, could provide enough quantity of caffeic acid derivatives for their multiple uses, besides guaranteeing the preservation of the plants as a natural resource. In this review, the alternatives for the synthetic obtaining of esters and amides of caffeic acid by simple synthetic methods are shown.

\section{Conflicts of Interest}

The authors declare that they have no conflicts of interest.

\section{Acknowledgments}

This work was supported by Semilla Fund 2017 from the University of Aysén (OR-R), and Innovation Fund for Competitiveness (Fondo de Innovación para la Competitividad, FIC-Aysén 2017, BIP code 40000496) from the Regional Government of Aysén (GORE Aysén), Chile.

\section{References}

[1] B. Halliwell and J. M. C. Gutteridge, Free Radicals in Biology and Medicine, Oxford University Press, Oxford, NY, USA, 4th edition, 2007.

[2] H. Sies, "Polyphenols and health: update and perspectives," Archives of Biochemistry and Biophysics, vol. 501, no. 1, pp. 2-5, 2010.

[3] W. R. Bidlack, Phytochemicals as Bioactive Agents, CRC Press, NY, USA, 2000.

[4] Y. Yu, Y. Deng, B.-M. Lu, Y.-X. Liu, J. Li, and J.-K. Bao, "Green tea catechins: a fresh flavor to anticancer therapy," Apoptosis, vol. 19, no. 1, pp. 1-18, 2014.

[5] J. B. Chakraborty, S. K. Mahato, and K. Joshi et al., "Hydroxychavicol, a piper betle leaf component, induces apoptosis of CML cells through mitochondrial reactive oxygen species-dependent JNK and endothelial nitric oxide synthase activation and overrides imatinib resistance," Cancer Science, vol. 103, no. 1, pp. 88-99, 2012.

[6] S. Jariyawat, T. Thammapratip, and K. Suksen et al., "Induction of apoptosis in murine leukemia by diarylheptanoids from Curcuma comosa Roxb," Cell Biology and Toxicology, vol. 27, no. 6, pp. 413-423, 2011.

[7] F. A. Urra, M. Cordova-Delgado, and H. Pessoa-Mahana et al., "Mitochondria: a promising target for anticancer alkaloids,"
Current Topics in Medicinal Chemistry, vol. 13, no. 17, pp. 2171-2183, 2013.

[8] P. Jain, N. Kumar, and V. R. Josyula et al., "A study on the role of $(+)$-catechin in suppression of HepG2 proliferation via caspase dependent pathway and enhancement of its in vitro and in vivo cytotoxic potential through liposomal formulation," European Journal of Pharmaceutical Sciences, vol. 50, no. 3-4, pp. 353-365, 2013.

[9] J. Teixeira, P. Soares, and S. Benfeito et al., "Rational discovery and development of a mitochondria-targeted antioxidant based on cinnamic acid scaffold," Free Radical Research, vol. 46, no. 5, pp. 600-611, 2012.

[10] C. Plaza, M. Pavani, and M. Faundez et al., "Inhibitory effect of nordihydroguaiaretic acid and its tetra-acetylated derivative on respiration and growth of adenocarcinoma TA3 and its multiresistant variant TA3MTX-R," In Vivo, vol. 22, no. 3, pp. 353-361, 2008.

[11] J. Monga, C. S. Chauhan, and M. Sharma, "Human breast adenocarcinoma cytotoxicity and modulation of 7,12-dimethylbenz[a]anthracene-induced mammary carcinoma in balb/c mice by Acacia catechu (L.f.) wild heartwood," Integrative Cancer Therapies, vol. 12, no. 4, pp. 347-362, 2013.

[12] M. Lang, R. Henson, C. Braconi, and T. Patel, "Epigallocatechingallate modulates chemotherapy-induced apoptosis in human cholangiocarcinoma cells," Liver International, vol. 29, no. 5, pp. 670-677, 2009.

[13] M. Saez-Ayala, M. P. Fernandez-Perez, S. Chazarra, N. McHedlishvili, A. Tarraga-Tomas, and J. N. Rodriguez-Lopez, "Factors influencing the antifolate activity of synthetic teaderived catechins," Molecules, vol. 18, no. 7, pp. 8319-8341, 2013.

[14] F. Jana, F. Faini, and M. Lapier et al., "Tumor cell death induced by the inhibition of mitochondrial electron transport: the effect of 3-hydroxybakuchiol hydroxybakuchiol," Toxicology and Applied Pharmacology, vol. 272, no. 2, pp. 356-364, 2013.

[15] I. Ali, F. G. Khan, and K. A. Suri et al., "In vitro antifungal activity of hydroxychavicol isolated from Piper betle L," Annals of Clinical Microbiology and Antimicrobials, vol. 9, no. 1, p. 7, 2010

[16] B. Roy, A. Chakraborty, S. K. Ghosh, and A. Basak, "Design, synthesis and bioactivity of catechin/epicatechin and 2 -azetidinone derived chimeric molecules," Bioorganic \& Medicinal Chemistry Letters, vol. 19, no. 24, pp. 7007-7010, 2009.

[17] C. E. Maddox, L. M. Laur, and L. Tian, "Antibacterial activity of phenolic compounds against the phytopathogen Xylella fastidiosa," Current Microbiology, vol. 60, no. 1, pp. 53-58, 2010.

[18] J. M. Silván, E. Mingo, M. Hidalgo, S. de Pascual-Teresa, A. V. Carrascosa, and A. J. Martinez-Rodriguez, "Antibacterial activity of a grape seed extract and its fractions against Campylobacter spp," Food Control, vol. 29, no. 1, pp. 25-31, 2013.

[19] R. Qin, K. Xiao, and B. Li et al., "The combination of catechin and epicatechin gallate from fructus crataegi potentiates $\beta$-lactam antibiotics against Methicillin-resistant Staphylococcus aureus (MRSA) in vitro and in vivo," International Journal of Molecular Sciences, vol. 14, no. 1, pp. 1802-1821, 2013.

[20] J. L. Pollock, L. A. Kogan, A. S. Thorpe, and W. E. Holben, " $( \pm)$-catechin, a root exudate of the invasive Centaurea stoebe lam. (spotted knapweed) exhibits bacteriostatic activity against multiple soil bacterial populations," Journal of Chemical Ecology, vol. 37, no. 9, pp. 1044-1053, 2011. 
[21] C. Cueva, S. Mingo, and I. Munoz-Gonzalez et al., "Antibacterial activity of wine phenolic compounds and oenological extracts against potential respiratory pathogens," Letters in Applied Microbiology, vol. 54, no. 6, pp. 557-563, 2012.

[22] R. Díaz-Gómez, R. López-Solís, E. Obreque-Slier, and H. Toledo-Araya, "Comparative antibacterial effect of gallic acid and catechin against Helicobacter pylori," LWT - Food Science and Technology, vol. 54, no. 2, pp. 331-335, 2013.

[23] H. Hussain, A. Badawy, and A. Elshazly et al., "Chemical constituents and antimicrobial activity of Salix subserrata," Records of Natural Products, vol. 5, no. 2, pp. 133-137, 2011.

[24] S. K. Berezin and J. T. Davis, "Catechols as membrane anion transporters," Journal of the American Chemical Society, vol. 131, no. 7, pp. 2458-2459, 2009.

[25] H. Mitsuda, M. Miyazaki, and I. B. Nielsen et al., "Evidence for catechol ring- induced conformational restriction in neurotransmitters," The Journal of Physical Chemistry Letters, vol. 1, no. 7, pp. 1130-1133, 2010.

[26] M. N. Clifford, "Chlorogenic acids and other cinnamates - nature, occurrence, dietary burden, absorption and metabolism," Journal of the Science of Food and Agriculture, vol. 80, no. 7, pp. 1033-1043, 2000.

[27] T. Ohkawara, H. Takeda, and J. Nishihira, "Protective effect of chlorogenic acid on the inflammatory damage of pancreas and lung in mice with l-arginine-induced pancreatitis," Life Sciences, vol. 190, pp. 91-96, 2017.

[28] J. Nie, Y. Chang, and Y. Li et al., "Caffeic acid phenethyl ester (propolis extract) ameliorates insulin resistance by inhibiting JNK and NF- $\kappa$ B inflammatory pathways in diabetic mice and HepG2 cell models," Journal of Agricultural and Food Chemistry, vol. 65, no. 41, pp. 9041-9053, 2017.

[29] N. Ali, S. Rashid, and S. Nafees et al., "Protective effect of chlorogenic acid against methotrexate induced oxidative stress, inflammation and apoptosis in rat liver: an experimental approach," Chemico-Biological Interactions, vol. 272, pp. 80-91, 2017.

[30] O. M. Agunloye and G. Oboh, "Caffeic acid and chlorogenic acid: evaluation of antioxidant effect and inhibition of key enzymes linked with hypertension," Journal of Food Biochemistry, vol. 42, no. 4, e12541 pages, 2018.

[31] E. R. Prudêncio, C. M. Cardoso, R. N. Castro, and C. J. Riger, "Antioxidant effect of caffeic acid derivatives on sod and glutathione defective yeasts," Applied Biochemistry and Microbiology, vol. 55, no. 3, pp. 264-269, 2019.

[32] M.-T.Huang, W. Ma, and P. Yen et al., "Inhibitory effects of caffeic acid phenethyl ester (CAPE) on 12-O-tetradecanoylphorbol13-acetate-induced tumor promotion in mouse skin and the synthesis of DNA, RNA and protein in HeLa cells," Carcinogenesis, vol. 17, no. 4, pp. 761-765, 1996.

[33] W. Li, N. Li, and Y. Tang et al., "Biological activity evaluation and structure-activity relationships analysis of ferulic acid and caffeic acid derivatives for anticancer," Bioorganic \& Medicinal Chemistry Letters, vol. 22, no. 19, pp. 6085-6088, 2012.

[34] C. Balachandran, N. Emi, and Y. Arun et al., "In vitro anticancer activity of methyl caffeate isolated from Solanum torvum swartz. fruit," Chemico-Biological Interactions, vol. 242, pp. 81-90, 2015.

[35] H. N. Lee, J.-K. Kim, and J. H. Kim et al., "A mechanistic study on the anti-cancer activity of ethyl caffeate in human ovarian cancer SKOV-3 cells," Chemico-Biological Interactions, vol. 219, pp. 151-158, 2014.
[36] J. Wang, S.-S. Gu, and N. Pang et al., "Alkyl caffeates improve the antioxidant activity, antitumor property and oxidation stability of edible oil," PLOS ONE, vol. 9, no. 4, e95909 pages, 2014.

[37] L. P. Pelinson, C. E. Assmann, and T. V. Palma et al., "Antiproliferative and apoptotic effects of caffeic acid on SKMel-28 human melanoma cancer cells," Molecular Biology Reports, vol. 46, no. 2, pp. 2085-2092, 2019.

[38] C. Omene, M. Patel, K. Karagoz, M.L. Gatza, and M. H. Barcellos-Hoff, "Abstract P4-07-03: immunomodulation of triple negative breast cancer by caffeic acid phenethyl ester (CAPE)," Cancer Research, vol. 79, no. 4, 2019.

[39] K. M. M. Espíndola, R. G. Ferreira, and L. E. M. Narvaez et al., "Chemical and pharmacological aspects of caffeic acid and its activity in hepatocarcinoma," Frontiers in Oncology, vol. 9, 2019.

[40] K. Misra, A. Nag, and A. Sonawane, "N-(2-Bromo-4fluorophenyl)-3-(3,4-dihydroxyphenyl)-acrylamide (CPAM), a small catecholic amide as an antioxidant, anti diabetic and antibacterial compound," RSC Advances, vol. 6, no. 106, pp. 104632-104641, 2016.

[41] K. Misra, H. S. Maity, A. Nag, and A. Sonawane, "Radical scavenging and antibacterial activity of caffemides against gram positive, gram negative and clinical drug resistance bacteria," Bioorganic \& Medicinal Chemistry Letters, vol. 26, no. 24, pp. 5943-5946, 2016.

[42] M. O. Araújo, H. L. Freire Pessoa, A. B. Lira, Y. P. Castillo, and D. P. de Sousa, "Synthesis, antibacterial evaluation, and QSAR of caffeic acid derivatives," Journal of Chemistry, vol. 2019, Article ID 3408315, 9 pages, 2019.

[43] G. Oboh, O. O. Adeoyo, A. O. Ademosun, O. B. Ogunsuyi, and O. M. Agunloye, "Effect of combinations of caffeine and caffeic acid on key enzymes linked to hypertension (in vitro)," Oriental Pharmacy and Experimental Medicine, vol. 18, no. 3, pp. 247-255, 2018.

[44] P. Rajan, I. Vedernikova, P. Cos, D. Vanden Berghe, K. Augustyns, and A. Haemers, "Synthesis and evaluation of caffeic acid amides as antioxidants," Bioorganic \& Medicinal Chemistry Letters, vol. 11, no. 2, pp. 215-217, 2001.

[45] J. Fu, K. Cheng, Z.-M. Zhang, R.-Q. Fang, and H.-L. Zhu, "Synthesis, structure and structure-activity relationship analysis of caffeic acid amides as potential antimicrobials," European Journal of Medicinal Chemistry, vol. 45, no. 6, pp. 2638-2643, 2010.

[46] Z.-H. Shi, N.-G. Li, and Q.-P. Shi et al., "Synthesis and structureactivity relationship analysis of caffeic acid amides as selective matrix metalloproteinase inhibitors," Bioorganic \& Medicinal Chemistry Letters, vol. 23, no. 5, pp. 1206-1211, 2013.

[47] A. Jitareanu, G. Tataringa, A.-M. Zbancioc, C. Tuchilus, M. Balan-Porcarasu, and U. Stanescu, "Cinnamic acid derivatives and 4-aminoantipyrine amides - synthesis and evaluation of biological Properties," Research Journal of Chemical Sciences, vol. 3, no. 3, pp. 9-13, 2013.

[48] D. Fancelli, A. Abate, and R. Amici et al., "Cinnamic anilides as new mitochondrial permeability transition pore inhibitors endowed with ischemia-reperfusion injury protective effect in vivo," Journal of Medicinal Chemistry, vol. 57, no. 12, pp. 5333-5347, 2014.

[49] M. Arlorio, M. Locatelli, and F. Travaglia et al., "Roasting impact on the contents of clovamide (N-caffeoyl-L-DOPA) and the antioxidant activity of cocoa beans (Theobroma cacao L.)," Food Chemistry, vol. 106, no. 3, pp. 967-975, 2008. 
[50] L. Dai, C. Zang, and S. Tian et al., "Design, synthesis, and evaluation of caffeic acid amides as synergists to sensitize fluconazole-resistant Candida albicans to fluconazole," Bioorganic \& Medicinal Chemistry Letters, vol. 25, no. 1, pp. 34-37, 2015.

[51] Z. Chen, M. Digiacomo, and Y. Tu et al., "Discovery of novel rivastigmine-hydroxycinnamic acid hybrids as multi-targeted agents for Alzheimer's disease," European Journal of Medicinal Chemistry, vol. 125, pp. 784-792, 2017.

[52] Z. Liu, J. Fu, L. Shan, Q. Sun, and W. Zhang, "Synthesis, preliminary bioevaluation and computational analysis of caffeic acid analogues," International Journal of Molecular Sciences, vol. 15, no. 5, pp. 8808-8820, 2014.

[53] S. Li, W. Zhang, and Y. Yang et al., "Discovery of oral-available resveratrol-caffeic acid based hybrids inhibiting acetylated and phosphorylated STAT3 protein," European Journal of Medicinal Chemistry, vol. 124, pp. 1006-1018, 2016.

[54] M.-Y. Kwon, S.-M. Kim, and J. Park et al., "A caffeic acid-ferulic acid hybrid compound attenuates lipopolysaccharide-mediated inflammation in BV2 and RAW264.7 cells," Biochemical and Biophysical Research Communications, vol. 515, no. 4, pp. 565-571, 2019.

[55] H. Takahashi, B. C. Q. Nguyen, Y. Uto, M. Shahinozzaman, S. Tawata, and H. Maruta, "1,2,3-Triazolyl esterization of PAK1blocking propolis ingredients, artepillin $\mathrm{C}$ (ARC) and caffeic acid (CA), for boosting their anti-cancer/anti-PAK1 activities along with cell-permeability," Drug Discoveries \& Therapeutics, vol. 11, no. 2, pp. 104-109, 2017.

[56] L. Chen, Y. Jin, and H. Chen et al., "Discovery of caffeic acid phenethyl ester derivatives as novel myeloid differentiation protein 2 inhibitors for treatment of acute lung injury," European Journal of Medicinal Chemistry, vol. 143, pp. 361-375, 2018.

[57] E. Otero, E. García, and G. Palacios et al., "Triclosan-caffeic acid hybrids: synthesis, leishmanicidal, trypanocidal and cytotoxic activities," European Journal of Medicinal Chemistry, vol. 141, pp. 73-83, 2017.

[58] C. Yang, J. Zhao, Y. Cheng, X. C. Le, and J. Rong, "N-Propargyl caffeate amide (PACA) potentiates nerve growth factor (NGF)induced neurite outgrowth and attenuates 6-Hydroxydopamine (6-OHDA)-induced toxicity by activating the Nrf2/HO-1 pathway," ACS Chemical Neuroscience, vol. 6, no. 9, pp. 15601569, 2015.

[59] P. Wang, C. Liu, and T. Sanches et al., "Design and synthesis of novel nitrogen-containing polyhydroxylated aromatics as HIV-1 integrase inhibitors from caffeic acid phenethyl ester," Bioorganic \& Medicinal Chemistry Letters, vol. 19, no. 16, pp. 4574-4578, 2009.

[60] H. Cai, X. Huang, and S. Xu et al., "Discovery of novel hybrids of diaryl-1,2,4-triazoles and caffeic acid as dual inhibitors of cyclooxygenase-2 and 5-lipoxygenase for cancer therapy," European Journal of Medicinal Chemistry, vol. 108, pp. 89-103, 2016.

[61] M. Touaibia and M. Guay, "Natural product total synthesis in the organic laboratory: total synthesis of caffeic acid phenethyl ester (CAPE), a potent 5-lipoxygenase inhibitor from honeybee hives," Journal of Chemical Education, vol. 88, no. 4, pp. 473-475, 2011.

[62] K. S. Bhullar, G. Lassalle-Claux, M. Touaibia, and H. P. V. Rupasinghe, "Antihypertensive effect of caffeic acid and its analogs through dual renin-angiotensin-aldosterone system inhibition," European Journal of Pharmacology, vol. 730, pp. 125-132, 2014.
[63] J. T. Sanderson, H. Clabault, and C. Patton et al., "Antiproliferative, antiandrogenic and cytotoxic effects of novel caffeic acid derivatives in LNCaP human androgendependent prostate cancer cells," Bioorganic \& Medicinal Chemistry, vol. 21, no. 22, pp. 7182-7193, 2013.

[64] J. Stoekigt and M. H. Zenk, "Chemical syntheses and properties of hydroxycinnamoyl- coenzyme A derivatives," Zeitschrift für Naturforschung C, vol. 30, no. 5-6, pp. 352-358, 1975.

[65] A. Ishihara, K. Kojima, T. Fujita, Y. Yamamoto, and H. Nakajima, "New series of avenanthramides in oat seed," Bioscience, Biotechnology, and Biochemistry, vol. 78, no. 12, pp. 1975-1983, 2014.

[66] D. De Lucia, O. M. Lucio, and B. Musio et al., "Design, synthesis and evaluation of semi-synthetic triazole-containing caffeic acid analogues as 5-lipoxygenase inhibitors," European Journal of Medicinal Chemistry, vol. 101, pp. 573-583, 2015.

[67] J.A.Doiron, B. Métayer, and R.R.Richardetal., "Clicked cinnamic caffeic esters amides as radical scavengers and 5-lipoxygenase inhibitors," International Journal of Medicinal Chemistry, vol. 2014, Article ID 931756, 12 pages, 2014.

[68] H.-Z. Chen, Y.-B. Chen, and Y.-P. Lv et al., "Synthesis and antitumor activity of feruloyl and caffeoyl derivatives," Bioorganic \& Medicinal Chemistry Letters, vol. 24, no. 18, pp. 4367-4371, 2014.

[69] J. Teixeira, F. Cagide, and S. Benfeito et al., "Development of a mitochondriotropic antioxidant based on caffeic acid: proof of concept on cellular and mitochondrial oxidative stress models," Journal of Medicinal Chemistry, vol. 60, no. 16, pp. 7084-7098, 2017.

[70] Y.-S. Xu, C.-C. Zeng, X.-M. Li, R.-G. Zhong, and Y. Zeng, "Design, synthesis and $\mathrm{Cu} 2+$ recognition of $\beta$-diketoacid and quinoxalone derivatives bearing caffeoyl or galloyl moieties linked by arylamide as potential HIV integrase inhibitors," Chinese Journal of Chemistry, vol. 24, no. 8, pp. 1086-1094, 2006.

[71] L. Jazlya, V. D. Gangana, C.T. Chakrabortya, A.V. Tamhankarb, J.J. Kadamc, and S.M. Bhalekard, "Methyl caffeate ether derivatives as future potential drug," Journal of Chemical, Biological and Physical Sciences Section A, vol. 4, pp. 139-146, 2014.

[72] K.-M. Shin, I.-T. Kim, and Y.-M. Park et al., "Anti-inflammatory effect of caffeic acid methyl ester and its mode of action through the inhibition of prostaglandin E2, nitric oxide and tumor necrosis factor- $\alpha$ production," Biochemical Pharmacology, vol. 68, no. 12, pp. 2327-2336, 2004.

[73] B. Etzenhouser, C. Hansch, S. Kapur, and C. D. Selassie, "Mechanism of toxicity of esters of caffeic and dihydrocaffeic acids," Bioorganic \& Medicinal Chemistry, vol. 9, no. 1, pp. 199-209, 2001.

[74] M. Andrade, S. Benfeito, and P. Soares et al., "Fine-tuning of the hydrophobicity of caffeic acid: studies on the antimicrobial activity against Staphylococcus aureus and Escherichia coli," RSC Advances, vol. 5, no. 66, pp. 53915-53925, 2015.

[75] D. Steverding, F. R. da Nobrega, S. A. Rushworth, and D. P. de Sousa, "Trypanocidal and cysteine protease inhibitory activity of isopentyl caffeate is not linked in Trypanosoma brucei," Parasitology Research, vol. 115, no. 11, pp. 4397-4403, 2016.

[76] C.-B. Yang, W.-J. Pei, J. Zhao, Y.-Y. Cheng, X.-H. Zheng, and J.-H. Rong, "Bornyl caffeate induces apoptosis in human breast cancer MCF-7 cells via the ROS- and JNK-mediated pathways," Acta Pharmacologica Sinica, vol. 35, no. 1, pp. 113-123, 2014. 
[77] A.-D. M. Sørensen, E. Durand, and M. Laguerre et al., "Antioxidant properties and efficacies of synthesized alkyl caffeates, ferulates, and coumarates," Journal of Agricultural and Food Chemistry, vol. 62, no. 52, pp. 12553-12562, 2014.

[78] F. de Campos Buzzi, C. L. Franzoi, and G. Antonini et al., "Antinociceptive properties of caffeic acid derivatives in mice," European Journal of Medicinal Chemistry, vol. 44, no. 11, pp. 4596-4602, 2009.

[79] L. C. Paracatu, C. Bonacorsi, and C.M. Quinello Gomes de Farias et al., "Alkyl caffeates as anti-helicobacter pylori and scavenger of oxidants produced by neutrophils," Medicinal Chemistry, vol. 10, no. 1, pp. 74-80, 2014.

[80] J. Zhang, L.-X. Xu, X.-S. Xu, B.-W. Li, R. Wang, and J.-J. Fu, "Synthesis and effects of new caffeic acid derivatives on nitric oxide production in lipopolysaccharide-induced RAW 264.7 macrophages," International Journal of Clinical and Experimental Medicine, vol. 7, no. 4, pp. 1022-1027, 2014.

[81] C.-H. Jia, J.-A. Shin, and K.-T. Lee, "Effects of caffeic acid phenethyl ester and 4-vinylcatechol on the stabilities of oil-inwater emulsions of stripped soybean oil," Journal of Agricultural and Food Chemistry, vol. 63, no. 47, pp. 10280-10286, 2015.

[82] D. N. Iqbal, E. A. Hussain, and N. Naz, "Synthesis and characterization of guar gum derivatives with antioxidant moieties," International Journal of Pharma and Bio Sciences, vol. 4, no. 4, pp. 305-316, 2013.

[83] A. Chyba, V. Mastihuba, and M. Mastihubová, "Synthesis of 4-nitrophenyl caffeate and its use in assays of caffeoyl esterases," Analytical Biochemistry, vol. 445, pp. 49-53, 2014.

[84] D. I. Batovska, T. Kishimoto, V. S. Bankova, Z. G. Kamenarska, and M. Ubukata, "Synthesis of some phenylpropanoid monoglycerides via the mitsunobu protocol," Molecules, vol. 10, no. 3, pp. 552-558, 2005.

[85] G. Appendino, A. Minassi, N. Daddario, F. Bianchi, and G. C. Tron, "Chemoselective esterification of phenolic acids and alcohols," Organic Letters, vol. 4, no. 22, pp. 3839-3841, 2002.

[86] L. Chapado, P. J. Linares-Palomino, S. Salido, J. Altarejos, J. A. Rosado, and G. M. Salido, "Synthesis and evaluation of the platelet antiaggregant properties of phenolic antioxidants structurally related to rosmarinic acid," Bioorganic Chemistry, vol. 38, no. 3, pp. 108-114, 2010.

[87] S. H. E. Ketabforoosh, M. Amini, and M. Vosooghi, A. Shafiee, E. Azizi, and F. Kobarfard, "Synthesis evaluation of anticancer activity and QSAR study of heterocyclic esters of caffeic acid," Iranian Journal of Pharmaceutical Research, vol. 12, no. 4, pp. 705-719, 2013.

[88] N. P. Alza, A. P. Murray, and G. A. Salvador, "Cativic acidcaffeic acid hybrid exerts cytotoxic effects and induces apoptotic death in human neuroblastoma cells," NaunynSchmiedeberg's Archives of Pharmacology, vol. 390, no. 12, pp. 1229-1238, 2017.

[89] Z. Tan and F. Shahidi, "A novel chemoenzymatic synthesis of phytosteryl caffeates and assessment of their antioxidant activity," Food Chemistry, vol. 133, no. 4, pp. 1427-1434, 2012.

[90] N. Pang, S.-S. Gu, and J. Wang et al., "A novel chemoenzymatic synthesis of propyl caffeate using lipase-catalyzed transesterification in ionic liquid," Bioresource Technology, vol. 139, pp. 337-342, 2013.

[91] A. Chyba, V. Mastihuba, and M. Mastihubová, "Effective enzymatic caffeoylation of natural glucopyranosides," Bioorganic \& Medicinal Chemistry Letters, vol. 26, no. 6, pp. 1567-1570, 2016.
[92] D.-A. Chou, Y.-H. Kuo, and M.-S. Jan et al., "Caffeate derivatives induce apoptosis in COLO 205 human colorectal carcinoma cells through Fas- and mitochondria-mediated pathways," Food Chemistry, vol. 131, no. 4, pp. 1460-1465, 2012.

[93] T. Nagaoka, A. H. Banskota, Y. Tezuka, I. Saiki, and S. Kadota, "Selective antiproliferative activity of caffeic acid phenethyl ester analogues on highly liver-metastatic murine colon 26L5 carcinoma cell line," Bioorganic \& Medicinal Chemistry, vol. 10, no. 10, pp. 3351-3359, 2002.

[94] H. Shi, D. Xie, R. Yang, and Y. Cheng, "Synthesis of caffeic acid phenethyl ester derivatives, and their cytoprotective and neuritogenic activities in PC12 cells," Journal of Agricultural and Food Chemistry, vol. 62, no. 22, pp. 5046-5053, 2014.

[95] Y.-C. Chen, Y.-H. Kuo, N.-C. Yang, C.-W. Liu, W.-T. Chang, and C.-L. Hsu, "Cytotoxic and apoptotic effects of caffeate derivatives on A549 human lung carcinoma cells," Journal of the Chinese Medical Association, vol. 77, no. 10, pp. 535-543, 2014.

[96] K. Uwai, Y. Osanai, T. Imaizumi, S.-I. Kanno, M. Takeshita, and M. Ishikawa, "Inhibitory effect of the alkyl side chain of caffeic acid analogues on lipopolysaccharide-induced nitric oxide production in RAW264.7 macrophages," Bioorganic \& Medicinal Chemistry, vol. 16, no. 16, pp. 7795-7803, 2008.

[97] L. M. LeBlanc, A. F. Paré, J. Jean-François, M. J. G. Hébert, M. E. Surette, and M. Touaibia, "Synthesis and antiradical/ antioxidant activities of caffeic acid phenethyl ester and its related propionic, acetic, and benzoic acid analoguesc," Molecules, vol. 17, no. 12, pp. 14637-14650, 2012.

[98] L. H. Boudreau, N. Picot, and J. Doiron et al., "Caffeoyl and cinnamoyl clusters with anti-inflammatory and anti-cancer effects. synthesis and structure-activity relationship," New Journal of Chemistry, vol. 33, pp. 1932-1940, 2009.

[99] V. Sinisi, K. Boronová, S. Colomban, L. Navarini, F. Berti, and C. Forzato, "Synthesis of Mono-, Di-, and Tri-3,4dimethoxycinnamoyl-1,5- $\gamma$-quinides," European Journal of Organic Chemistry, vol. 2014, no. 6, pp. 1321-1326, 2014.

[100] E. Rattanangkool, P. Kittikhunnatham, T. Damsud, S. Wacharasindhu, and P. Phuwapraisirisan, "Quercitylcinnamates, a new series of antidiabetic bioconjugates possessing $\alpha$ glucosidase inhibition and antioxidant," European Journal of Medicinal Chemistry, vol. 66, pp. 296-304, 2013.

[101] J. Yang, G. A. Marriner, X. Wang, P. D. Bowman, S. M. Kerwin, and S. Stavchansky, "Synthesis of a series of caffeic acid phenethyl amide (CAPA) fluorinated derivatives: comparison of cytoprotective effects to caffeic acid phenethyl ester (CAPE)," Bioorganic \& Medicinal Chemistry, vol. 18, no. 14, pp. 5032-5038, 2010.

[102] D. Xie, F. Yang, J. Xie, M. Zhang, W. Liu, and L. Fu, "A rapid and practical catalytic esterification for the preparation of caffeic acid esters," Journal of Chemical Research, vol. 38, no. 11, pp. 695-700, 2014.

[103] K. Takahashi, Y. Yoshioka, and E. Kato et al., "Methyl caffeate as an $\alpha$-glucosidase inhibitor from Solanum torvum fruits and the activity of related compounds," Bioscience, Biotechnology, and Biochemistry, vol. 74, no. 4, pp. 741-745, 2010.

[104] J. Glaser, M. Schultheis, and S. Hazra et al., "Antileishmanial lead structures from nature: analysis of structure-activity relationships of a compound library derived from caffeic acid bornyl ester," Molecules, vol. 19, no. 2, pp. 1394-1410, 2014.

[105] C.-N. Xia, H.-B. Li, and F. liu, W.-X. Hu, "Synthesis of transcaffeate analogues and their bioactivities against HIV-1 integrase and cancer cell lines," Bioorganic \& Medicinal Chemistry Letters, vol. 18, no. 24, pp. 6553-6557, 2008. 
[106] H. Wang, Q.-Y. Wei, H. Jiang, and Z.-H. Jiang, "One-pot preparation of phenylpropanoid esters co-catalyzed by boric acid and piperidine," Research on Chemical Intermediates, vol. 38, no. 1, pp. 207-213, 2012.

[107] R. Hosseini, F. Moosavi, and H. Rajaian et al., "Discovery of neurotrophic agents based on hydroxycinnamic acid scaffold," Chemical Biology \& Drug Design, vol. 88, no. 6, pp. 926-937, 2016.

[108] M. Costa, S. Losada-Barreiro, F. Paiva-Martins, and C. BravoDíaz, "Physical evidence that the variations in the efficiency of homologous series of antioxidants in emulsions are a result of differences in their distribution," Journal of the Science of Food and Agriculture, vol. 97, no. 2, pp. 564-571, 2017.

[109] W.-X. Hu, C.-N. Xia, G.-H. Wang, and W. Zhou, "One-pot preparation of caffeic acid esters from 3, 4-dihydroxybenzaldehyde," Journal of Chemical Research, vol. 2006, no. 9, pp. 586-588, 2006.

[110] Z. Zhang, B. Xiao, Q. Chen, and X.-Y. Lian, "Synthesis and biological evaluation of caffeic acid 3,4-dihydroxyphenethyl ester," Journal of Natural Products, vol. 73, no. 2, pp. 252-254, 2010.

[111] M. Sechi, F. Casu, I. Campesi, S. Fiori, and A. Mariani, "Hyperbranched molecular structures with potential antiviral activity: derivatives of 5,6-dihydroxyindole-2-carboxylic acid," Molecules, vol. 11, no. 12, pp. 968-977, 2006.

[112] M. Sechi, G. Angotzi, and R. Dallocchio et al., "Design and synthesis of novel dihydroxyindole-2-carboxylic acids as HIV1 integrase inhibitors," Antiviral Chemistry and Chemotherapy, vol. 15, no. 2, pp. 67-81, 2004.

[113] N. Rodrigues, K. Bennis, and D. Vivier et al., "Synthesis and structure-activity relationship study of substituted caffeate esters as antinociceptive agents modulating the TREK-1 channel," European Journal of Medicinal Chemistry, vol. 75, pp. 391-402, 2014.

[114] M. Nardini, F. Leonardi, C. Scaccini, and F. Virgili, "Modulation of ceramide-induced NF- $\kappa \mathrm{B}$ binding activity and apoptotic response by caffeic acid in U937 cells: comparison with other antioxidants," Free Radical Biology and Medicine, vol. 30, no. 7, pp. 722-733, 2001.

[115] M. J. Chung, P. A. Walker, and C. Hogstrand, "Dietary phenolic antioxidants, caffeic acid and trolox, protect rainbow trout gill cells from nitric oxide-induced apoptosis," Aquatic Toxicology, vol. 80, no. 4, pp. 321-328, 2006.

[116] G. Hsiao, M.-Y. Shen, and W.-C. Chang et al., "A novel antioxidant, octyl caffeate, suppression of LPS/IFN- $\gamma$-induced inducible nitric oxide synthase gene expression in rat aortic smooth muscle cells," Biochemical Pharmacology, vol. 65, no. 8, pp. 1383-1392, 2003.

[117] J. Kyselka, D. Rabiej, and M. Dragoun et al., "Antioxidant and antimicrobial activity of linseed lignans and phenolic acids," European Food Research and Technology, vol. 243, no. 9, pp. 1633-1644, 2017.

[118] R. Taguchi, K. Hatayama, and T. Takahashi et al., "Structureactivity relations of rosmarinic acid derivatives for the amyloid $\beta$ aggregation inhibition and antioxidant properties," European Journal of Medicinal Chemistry, vol. 138, pp. 1066-1075, 2017.

[119] A. M. O. Amoussa, L. Lagnika, M. Bourjot, C. VonthronSenecheau, and A. Sanni, "Triterpenoids from Acacia ataxacantha DC: antimicrobial and antioxidant activities," $B M C$ Complementary and Alternative Medicine, vol. 16, no. 1, Article ID 284, 2016.
[120] R. Gandolfi, A. Contini, and D. Pinto et al., "Synthesis and biological evaluation of new natural phenolic $(2 E, 4 E, 6 E)$-octa2,4,6-trienoic esters," Chemistry \& Biodiversity, vol. 14, no. 12, e1700294 pages, 2017.

[121] A. B. Lira, C. D. A. Montenegro, and K. M. de Oliveira et al., "Isopropyl caffeate: a caffeic acid derivative-antioxidant potential and toxicity," Oxidative Medicine and Cellular Longevity, vol. 2018, Article ID 6179427, 14 pages, 2018.

[122] K.Pérez-Cruz,M.Moncada-Basualto, and J.Morales-Valenzuela et al., "Synthesis and antioxidant study of new polyphenolic hybrid-coumarins," Arabian Journal of Chemistry, vol. 11, no. 4, pp. 525-537, 2017.

[123] J. A. Doiron, L. M. Leblanc, and M. J. G. Hébert et al., "Structure-activity relationship of caffeic acid phenethyl ester analogs as new 5-lipoxygenase inhibitors," Chemical Biology \& Drug Design, vol. 89, no. 4, pp. 514-528, 2017. 

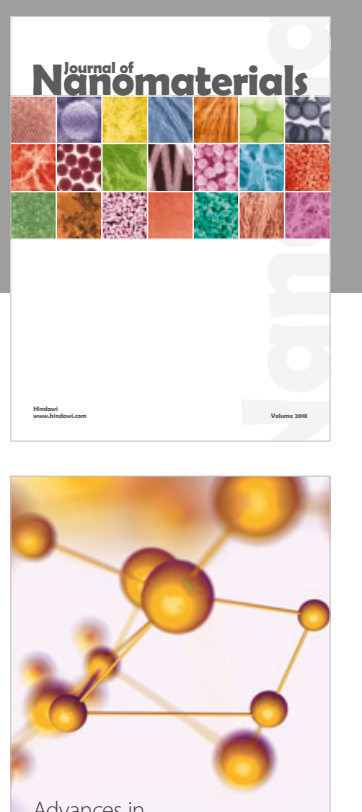

Physical Chemistry
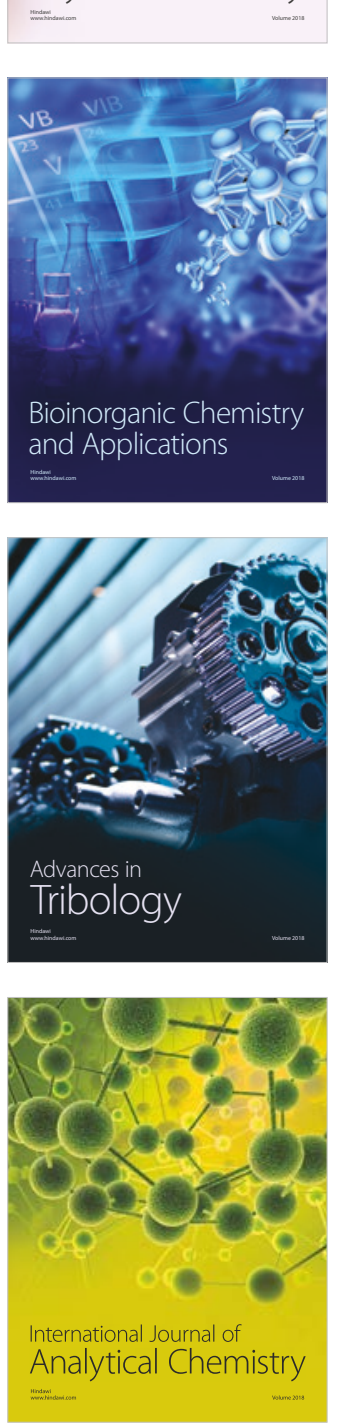

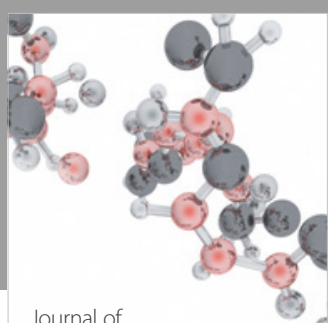

Analytical Methods

in Chemistry

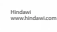

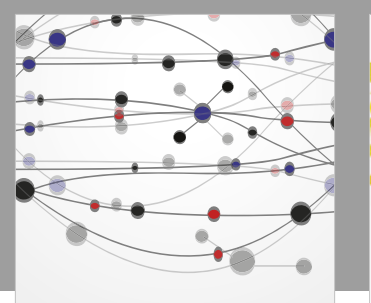

The Scientific World Journal

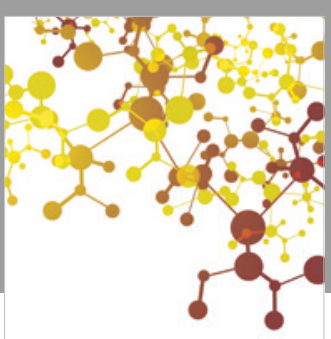

Journal of

Applied Chemistry
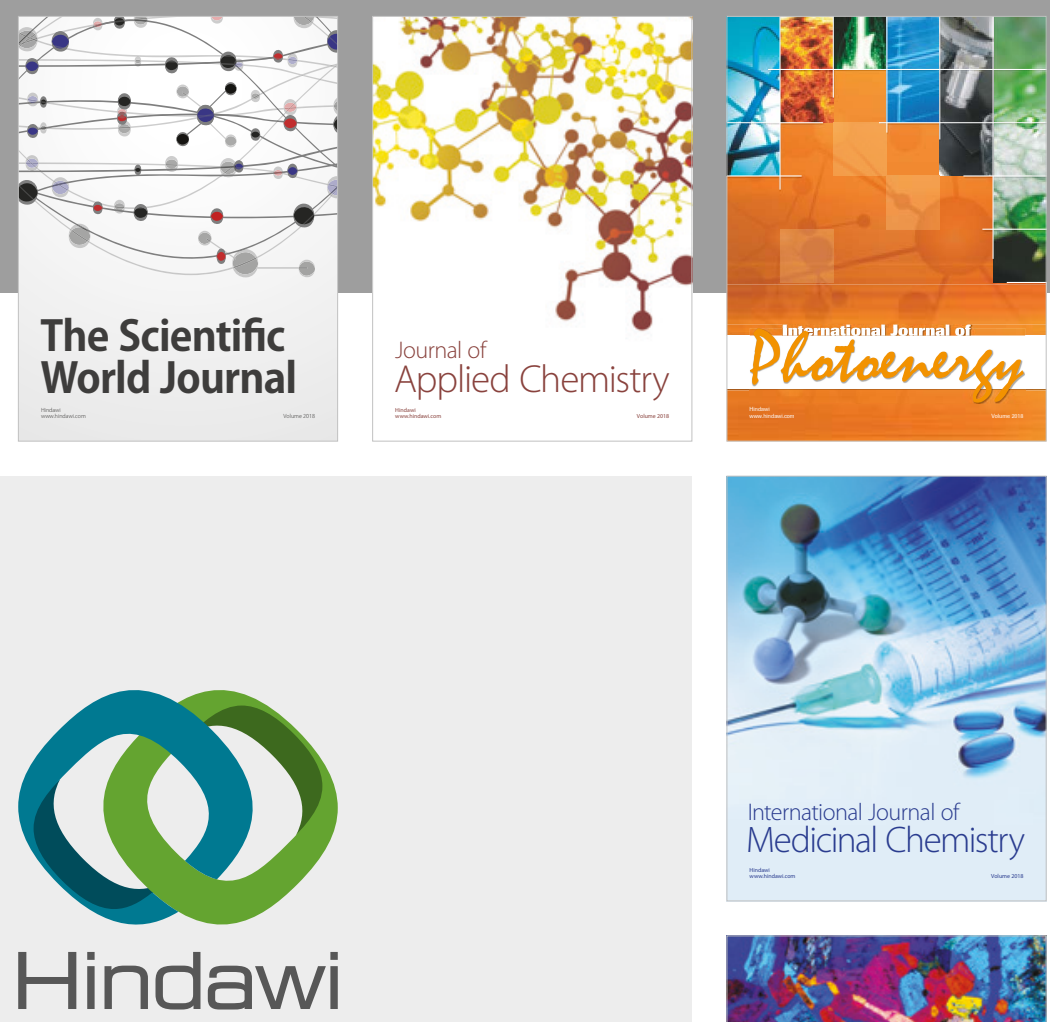

Submit your manuscripts at

www.hindawi.com
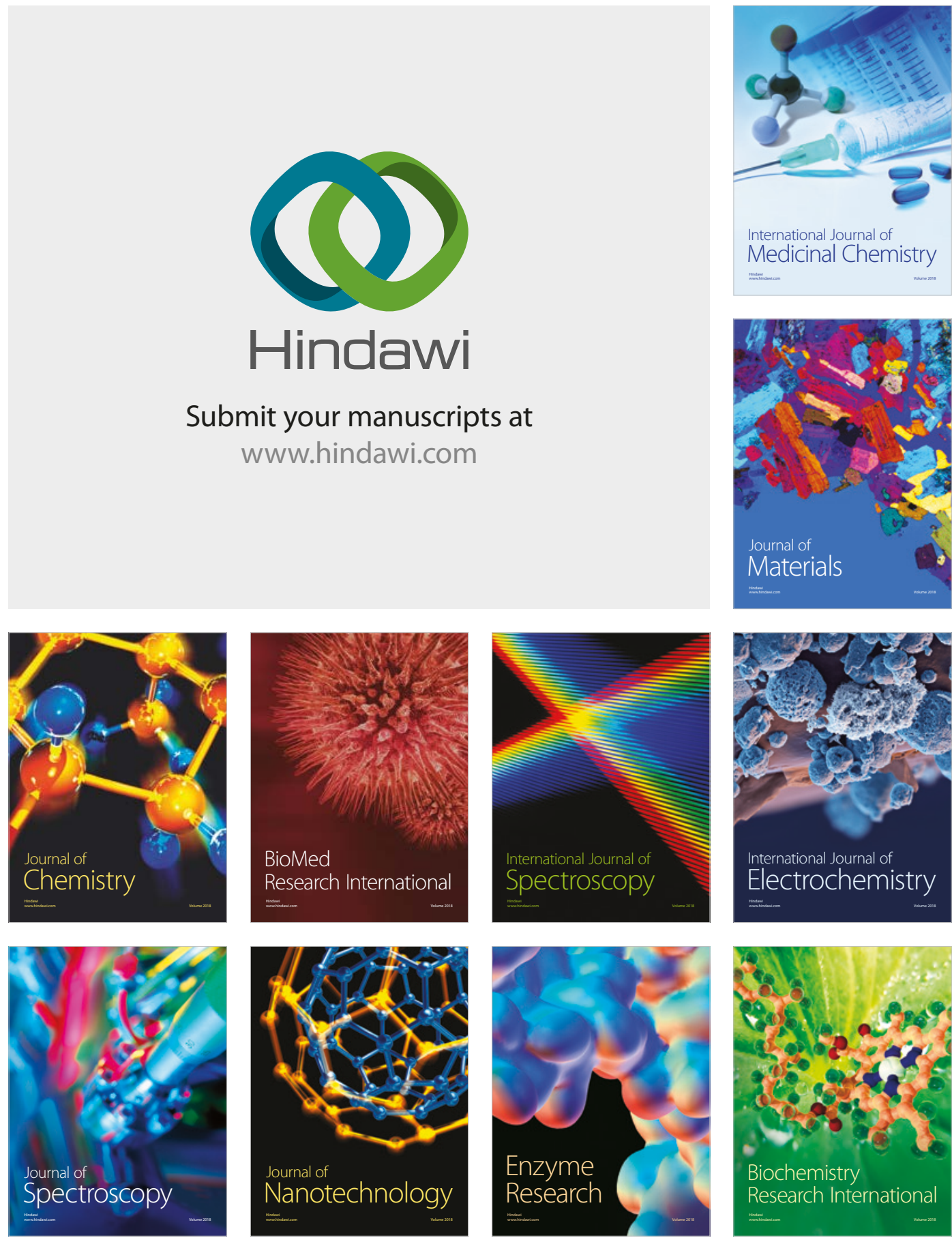
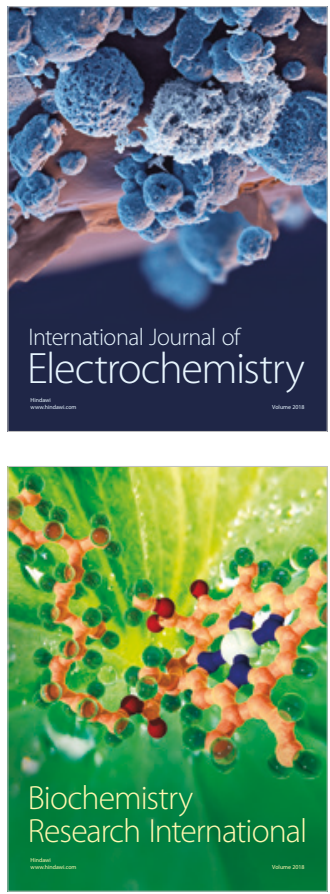